\title{
Energy Optimization for the Design of Corn-based Ethanol Plants
}

\author{
Ramkumar Karuppiah ${ }^{1}$, Andreas Peschel ${ }^{1}$, Mariano Martín ${ }^{2}$, Ignacio E. Grossmann ${ }^{1}$, \\ Wade Martinson ${ }^{3}$, Luca Zullo ${ }^{3}$
}

(1) Department of Chemical Engineering, Carnegie Mellon University, 5000 Forbes Avenue, Pittsburgh, PA 15213, USA

(2) Departamento de Ingeniería Química, Universidad de Salamanca, Plz. de los Caídos 1-5, Salamanca, 37008, Spain

(3) Cargill, Minneapolis, MN 55440, USA

\begin{abstract}
In this work we address the problem of optimizing corn-based bioethanol plants through the use of heat integration and mathematical programming techniques. The goal is to reduce the operating costs of the plant. Capital cost, energy usage, and yields all contribute to prduction cost. Yield and energy use also influence the viability of cornbased ethanol as a sustainable fuel. We first propose a limited superstructure of alternative designs including the various process units and utility streams involved in ethanol production. Our objective is to determine the connections in the network and the flow in each stream in the network such that we minimize the energy requirement of the overall plant. This is accomplished through the formulation of a mixed integer nonlinear programming problem involving mass and energy balances for all the units in the system, where the model is solved through two nonlinear programming subproblems. We then perform a heat integration study on the resulting flowsheet; the modified flowsheet includes multieffect distillation columns and further reduces energy consumption. The results indicate that it is possible to reduce the current steam consumption required in the transformation of corn into fuel grade ethanol by more than $40 \%$ compared to initial basic design.
\end{abstract}

Keywords: Bioethanol; Sustainability; Nonlinear programming; Multieffect distillation columns; Heat integration

\footnotetext{
* Corresponding author. Tel.: +1-412-268-3642; Fax: +1-412-268-7139.

Email address: grossmann@cmu.edu (I.E. Grossmann)
} 


\section{Introduction}

The supply of energy for various operations such as transportation, power generation and heating is of critical concern in the world today. Fossil fuels like crude oil that have been the traditional source of energy are non-renewable. Prices of fossil fuels like crude oil and natural gas have increased significantly in the past five years. This, along with increasing concerns about global warming, has led to a search for alternatives to fossil fuels. Hence, the use of new sources of energy like fuel cells, solar energy or bioethanol has become a priority. Bioethanol in particular shares some of the storage and distribution advantages of traditional fuels hold over other energy sources like hydrogen. Its production has increased all over the world in the last few years through both expansion of existing plants and construction of new facilities. In the United States it is usually produced using a technology called the "Dry-grind process" that utilizes corn kernels as feedstock to produce ethanol. As a result of the effort to sustainably substitute ethanol for gasoline as transportation fuel, the production of ethanol in the United States has risen up to 6 billion gallons per year in 2006 (Singh, 2006).

Historically, early internal combustion engines were built to run on a variety of fuels, including alcohols and alcohol-hydrocarbon blends (http://running on alcohol.tripod.com/id7.html, as of 12/09/2006). In 1907 the United States Department of Agriculture investigated the use of alcohol as a motor fuel. A subsequent study by the United States Bureau of Mines concluded that engines could provide up to $10 \%$ higher power on alcohol fuels than on gasoline. Mixtures of alcohol and gasoline were used on farms in the United States in the early 1900s. For transportation purposes, the first Ford Model $\mathrm{T}$ automobiles could be run on either gasoline or ethanol using a manually adjustable carburetor. However, the development of low cost gasoline displaced other automobile fuels and the diesel engine further solidified the hold of petroleum fuels on the transportation sector. Ethanol was occasionally used, particularly in rural regions, when gasoline supplies were short or when corn prices were low.

More recently Brazil has been producing bioethanol on a large scale and now runs most of its vehicles on ethanol-gasoline blends, thus proving the viability of ethanol as a fuel. It also provides proof that the market can accommodate a major shift in automative fuel. In the United States there are some Flexible Fuel Vehicles (FFVs) that run on a blend of ethanol and gasoline called E85 (85\% ethanol and 15\% gasoline). 
Fuel ethanol also presents some challenges. It is corrosive, and materials that normally would not be affected by low percentage ethanol blends, have been found to dissolve in the presence of higher ethanol concentrations. Dedicated ethanol vehicles must use unplated steel, stainless steel, black iron or bronze, which have all shown acceptable resistance to ethanol corrosion, or they have to use non-metallic materials such as thermoset reinforced fiberglass or neoprene rubber (IFQC, 2004).

The issue of feasibility of ethanol as a fuel has been under considerable debate. Early research indicated that the net energy balance in the production of corn-based ethanol is negative (Pimentel, 1991), in the sense that more energy is required to produce a unit of ethanol than what it provides when burned. More recent studies based on newer process data that also includes co-product energy credits indicate a positive net energy balance (Shapouri et al., 1995).

To improve the design and the energy efficiency of dry-grind ethanol plants, process synthesis and mathematical optimization techniques can be used (for optimal process synthesis problems see Grossmann et al., 1999). We propose a limited superstructure optimization approach where we first construct a flowsheet embedding the various process units involved in ethanol production, and then consider alternatives for some of the processes. These units are interconnected to each other through network flows and other utility streams. The goal is to optimize the structure minimizing the energy input in the ethanol production process. The optimization of the system is formulated as a mixed integer nonlinear programming (MINLP) problem, where the model involves a set of constraints representing mass and energy balances for all the units in the system. This problem is solved through two nonlinear programming (NLP) subproblems. We then perform a heat integration analysis of the resulting process. The heat recovery network, together with a modified distillation column design, further reduce the energy consumption in the plant and this decreased the unit production cost of ethanol. Finally, we present the results of a case study for the optimization of a network for producing fuel ethanol from corn.

\section{Overall Process Description}

A base case structure of a plant producing fuel ethanol from corn using the drygrind process appears in Fig. 1. 


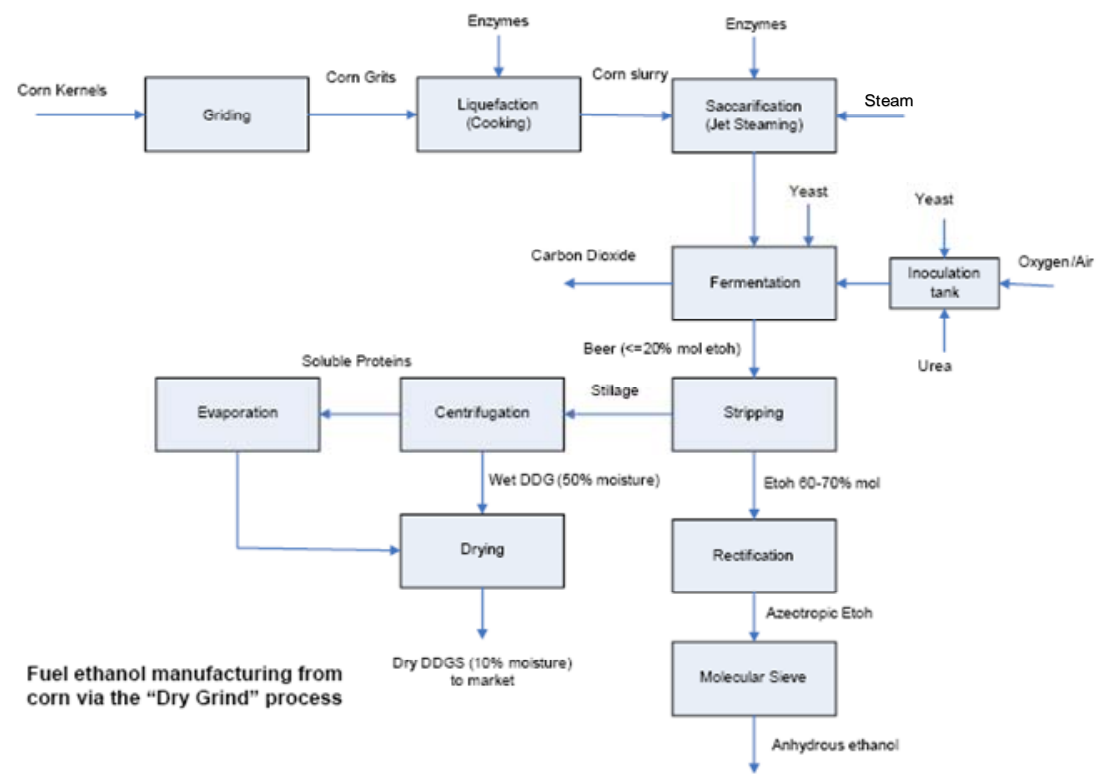

Fig. 1 Base case process flowsheet for ethanol manufacture from corn kernels

In this process, corn kernels are used as feed, and are first washed and then ground. The resulting ground corn undergoes cooking and liquefaction to produce corn slurry, which is then enzymatically saccharified to produce glucose. The mash is then fed to the fermentor where ethanol is produced from glucose. After the fermentation, a stripping column known as 'beer column' separates the solids and some water from the ethanol-water mixture. The beer column overhead stream contains $60-70 \%$ ethanol and is further rectified in a distillation tower to obtain an azeotropic mixture of ethanol and water. This azeotropic mixture then passes over a molecular sieve made of zeolite to produce anhydrous or fuel grade ethanol at the outlet. The wet solids from the bottom of the beer column go to a centrifuge, which separates the mixture into solids (relatively wet) and a liquid mixture. These wet solids from the bottom of the centrifuge are combined with the proteins obtained by evaporating the water from the centrifuge and are dried. This material (Distillers Dried Grains with Solubles, or, DDGS) is sold as cattle feed.

In the next section, alternatives are introduced for some of the processes in the standard flowsheet. This yields a superstructure of design alternatives that is optimized using nonlinear programs to minimize energy consumption in the plant. 


\section{Superstructure of Design Alternatives}

We propose a superstructure of the operations involved in the transformation of corn to fuel ethanol by considering a number of different design alternatives.

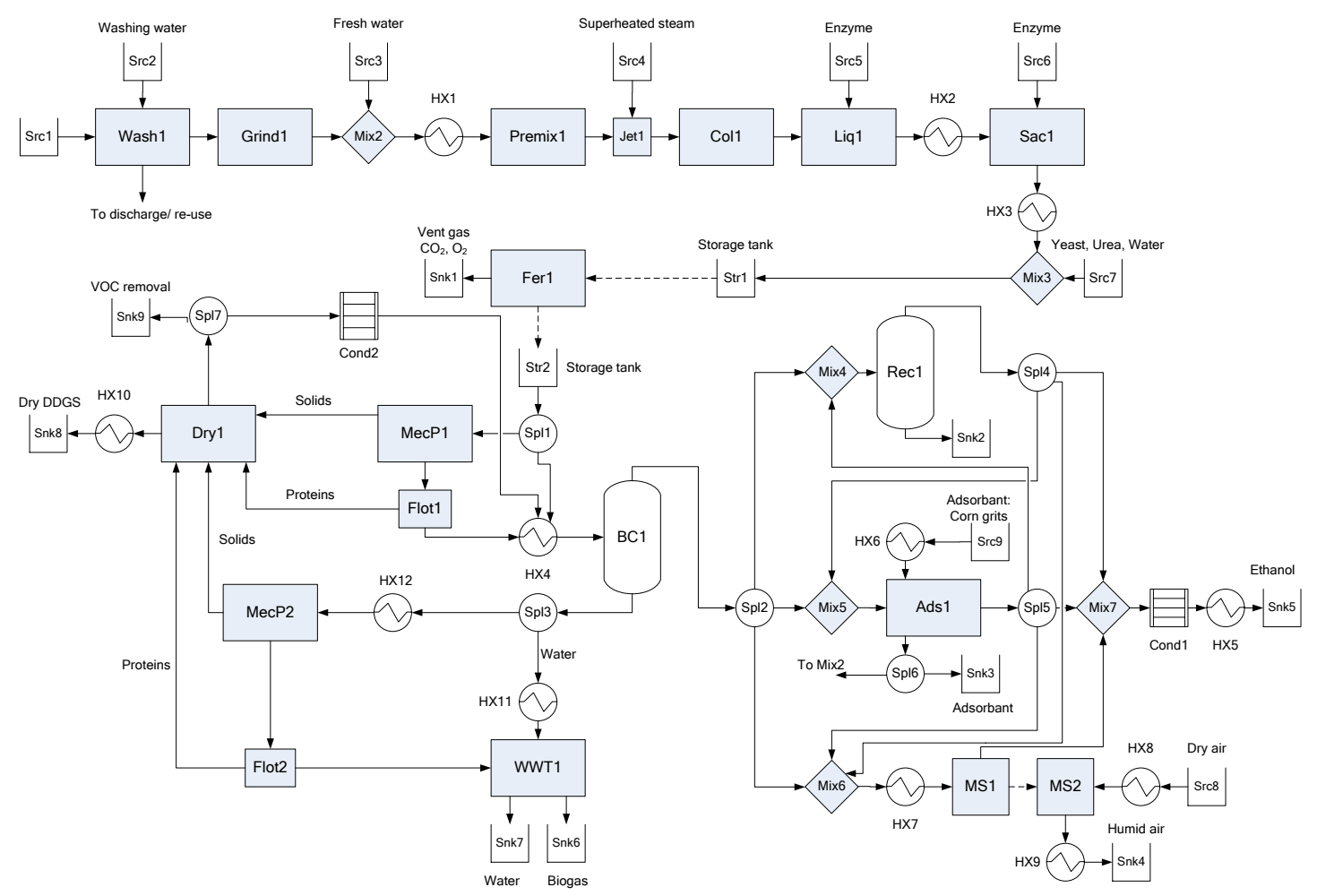

Fig. 2 Superstructure of a corn-based ethanol plant

As can be seen from Fig. 2, the superstructure has three specific sub-structures. These pertain to:

(i) Feed preparation and enzymatic hydrolysis - These are operations which are necessary for the production of ethanol, including corn washing and grinding, jet cooking, liquefaction, saccharification and fermentation.

(ii) Ethanol purification - This involves operations required for the purification of ethanol as obtained from the fermentor to fuel grade ethanol. This part consists of the distillation columns, corn bed adsorbers and molecular sieves.

(iii) Solids drying - These operations are for separating and drying the solids from the fermentor to be used as cattle feed. This part of the network includes the mechanical press, the flotation unit, and the dryer.

Corn kernels are used as feedstock in this fuel ethanol production process. An average composition of yellow-dent \#2 corn kernels appears in Table A1 in Appendix A. The corn kernels consist primarily of starch. Other components include free sugars, 
proteins, hemicellulose, cellulose, oils and ash. It is assumed that the sugars are only glucose. The cellulose and hemicellulose are mainly part of the fiber. The moisture content of the corn is taken to be $15 \%$. The feedstock is converted into the required product, which is nearly anhydrous ethanol following a series of steps.

There exist a number of different design alternatives in the superstructure. For instance, we have two different routes for separating the solids and liquids coming out of the fermentor as seen in Fig. 2. We can have a mechanical press (separator) placed at the outlet of the fermentor so that the solid-liquid separation takes place before the beer column. Alternatively, the separator can be placed after the bottoms of the distillation column, in which case the distillation process also provides the main solid-liquid separation. In the former separation route the solid loading to the distillation column is lower, while in the latter case the solid loading to the distillation column is higher.

For purifying the ethanol-water mixture coming out at the top of the beer column, we can use one or a combination of the following (see Fig. 2):

(a) Rectification column (distillation column that gives a azeotropic mixture of ethanol and water at the top).

(b) Molecular sieves (zeolite beds to selectively adsorb water from an incoming vapor mixture of ethanol and water).

(c) Corn grit adsorber (bed made of corn grits to selectively adsorb water from ethanol-water vapor mixture (see Ladisch et al., 1984)).

We model the various operations in the plant including the different alternatives to obtain an MINLP model, which is optimized with respect to the energy consumption per unit ethanol produced. Note that since we have just one discrete decision to be made (how to separate the solids from the liquid in the slurry coming out of the fermentor), we simply solve two separate NLP models, corresponding to each option, and choose the better solution. After the optimization we perform heat integration but find that the scope is limited. Therefore, we analyze the distillation columns in the network, which are energy intensive processes and replace them with multieffect distillation columns in order to reduce the energy consumption.Finally, we complete the design by performing heat integration (Yee and Grossmann, 1990). It should be noted that we have used a sequential optimization approach instead of a simultaneous one (Biegler et al., 1999) because the emphasis of this paper is to demonstrate the proof of concept and assess the potential of the optimization and energy reducing techniques in an ethanol plant. It will 
be shown that despite this sequential synthesis strategy, the combination of using optimization, multieffect distillation columns and heat integration in the plant can significantly reduce the energy consumption. Further improvements should be possible by considering a simultaneous approach.

\section{Model}

All the operations in the ethanol production process are modeled with equations. Models of the constituent units in the superstructure consist primarily of mass and energy balances. The data for the parameters used in the model is mostly taken from Jacques et al. (1999) and few other cited sources; the numerical data for other operating parameters represents current typical practice as estimated by Cargill. The model is written in terms of the total mass flows, component mass flows, component mass fractions, and temperatures of the streams in the network. These are the main variables whose values have to be determined from the optimization. In the model, $F$ (unit 1 , unit 2 ) denotes the total mass flow from unit1 to unit2 in the system in $\mathrm{kg} / \mathrm{s}$. The variable, $f c(j$,unit 1 ,unit 2$)$ stands for the mass flow of component $j$ from unit1 to unit 2 in the system in $\mathrm{kg} / \mathrm{s}$. The term $x(j$,unit 1 ,unit 2$)$ is the mass fraction of component $j$ in the stream from unit 1 to unit 2 in the system, while $T$ (unit1,unit 2 ) represents the temperature (in ${ }^{\circ} \mathrm{C}$ ) of the stream flowing from unit 1 and unit 2 in the network. The components in the system include those present in the corn, plus those produced during the process of ethanol production, and belong to the set $J=\{$ water, starch, glucose, maltose, proteins, ethanol, glycerol, succinic acid, acetic acid, lactic acid, urea, cell mass, carbon dioxide, oxygen, cellulose, hemicellulose, oil, ash $\}$. Starch, proteins, cellulose, hemicellulose, oil, ash and water are present in the corn feed. Maltose and glucose are intermediate products of the cooking process. Glycerol, succinic acid, acetic acid, and lactic acid are the main by-products of the fermentation process that produces ethanol. Carbon dioxide and oxygen are also by-products of the fermentation process. The yeast required for fermentation is denoted by cell mass. Urea is required as a nitrogen source for the growth of yeast. Finally, all enzymes used in the process are commonly represented as proteins. Note that the components glucose, maltose, proteins, ethanol, glycerol, acetic acid, lactic acid, and urea are assumed to be completely soluble in water. Starch, cell mass, cellulose, hemicellulose, oil, and ash are assumed to be insoluble in water. 
Carbon dioxide and oxygen are gaseous products, and therefore assumed not to be found in the liquid streams.

The set of equations that relate the component flows, total flows and component fractions in all the streams in the network are:

$$
\begin{aligned}
& f c(j, \text { unit } 1, \text { unit } 2)=x(j, \text { unit } 1, \text { unit } 2) * F(\text { unit } 1, \text { unit } 2) \quad \forall j \in J \\
& F(\text { unit } 1, \text { unit } 2)=\sum_{j} f c(j, \text { unit } 1, \text { unit } 2)
\end{aligned}
$$

The different units in the superstructure are modeled as described below.

(i) Mechanical preparation - Corn washing and grinding (see Fig. 3)

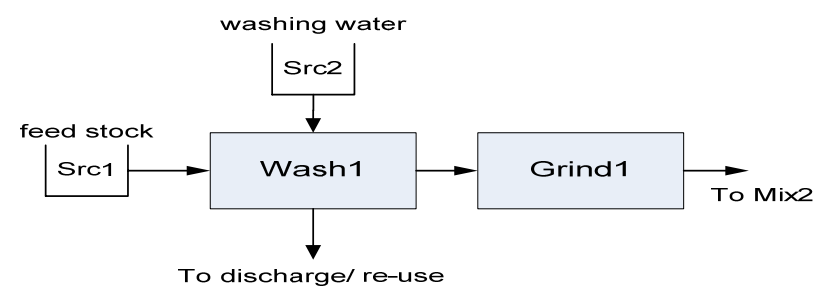

Fig. 3 Washing and grinding of corn kernels

The incoming feed of corn kernels (from source $S r c 1$ ) is first washed with a stream of freshwater with no contaminants inside a washing unit (Washl). This step removes dirt and dust from the corn kernels. The washing water (from source $S r c 2$ ) also slightly hydrates the corn. Therefore, a small amount (1\%) of the wash water is assumed to stay with the corn. The spent washing water is treated and discharged or used in other processes in the plant, although this option is not considered in the model. It is assumed that $0.5 \mathrm{~kg}$ of washing water is needed to wash $1 \mathrm{~kg}$ of corn kernels. The washing step does not consume any heat because it takes place at room temperature.

After this step, the corn is ground in a dry mill (denoted by Grind1). Grinding breaks up the corn kernels to obtain an optimal particle size for penetration of water during the corn cooking process. In most plants, hammer mills are used to break up the corn. The corn slurry should also not be too fine in order to avoid problems in the byproduct recovery and to avoid balling in the slurry tanks (Jacques et al., 1999). The milling step takes place at ambient temperatures, and therefore no heat is required in this process. The power consumption in the grinding process is taken into account in the cost analysis. It is to be noted that the corn composition remains unchanged during the grinding process. The mass and energy balances in these preliminary operations are given below.

$$
\begin{aligned}
& f_{c}(j, \text { Wash } 1, \text { Grind } 1)=f_{c}(j, \text { Src } 1, \text { Wash } 1) \quad \forall j \in J, j \neq\{\text { water }\} \\
& f_{c}(\text { water,Wash }, \text { Grind } 1)=f_{c}(\text { water, Srcl } 1, \text { Wash })+f r a c_{\text {wash }} . f_{c}(\text { water, Src } 2, \text { Wash })
\end{aligned}
$$




$$
\begin{aligned}
& f c(j, \operatorname{Src1}, \text { Wash } 1)=x_{0}(j) \cdot F(\operatorname{Src1} 1, \text { Wash } 1) \quad \forall j \in J \\
& F(\operatorname{Src} 2, \text { Wash } 1)=\min _{\text {wash }} . F(\operatorname{Src1}, \text { Wash } 1) \\
& f_{c}(j, \text { Grind } 1, \text { Mix } 2)=f c(j, \text { Wash } 1, \text { Grind } 1) \quad \forall j \in J
\end{aligned}
$$

In the above equations, $\min _{\text {wash }}$ stands for the minimum amount of washing water required per $\mathrm{kg}$ of corn, while $f_{r a c_{\text {wash }}}$ is the fraction of washing water that stays with the corn. $x_{0}(j)$ is the composition of the corn kernels feedstock on a wet basis.

(ii) Corn cooking

On average, $90 \%$ of the starch present in corn is in the form of amylopectin and $10 \%$ is in the straight-chain amylose form (Jacques et al., 1999). The granular structure of the starch must be broken down first to produce simple sugars, which can be fermented to produce ethanol. This is achieved by gelatinizing the slurry of ground corn kernels and water. When the slurry is cooked, the starch crystals adsorb water and swell. They lose their crystalline structure and the starch molecules become available for depolymerization. In this work the cooking process is considered to be continuous. Fig. 4 depicts the operations involved. The ground corn is mixed with water (from $S r c 3$ ) and heated up to $60^{\circ} \mathrm{C}$ using a heat exchanger $(H X 1)$ and mixed thorougly in a pre-mixing tank (denoted by Premixl). After this, the temperature of the slurry is raised to $120{ }^{\circ} \mathrm{C}$ by direct injection of superheated steam in a jet cooker (denoted by Jet 1). This steam is assumed to come from a source $\operatorname{Src4}$. Since steam is being added to the slurry in this cooker, it will have the effect of increasing the water fraction in the slurry at the outlet of the jet cooker. The corn mash is then fed to a vertical column (Coll), where its temperature is reduced to $85{ }^{\circ} \mathrm{C}$ in about 20 minutes (Jacques et al., 1999). In this column, the viscosity of the mash changes and the crystalline structure of the amylopectin is broken. The high temperature in the jet cooker and in the column also disinfects the mash and prevents microbial contamination in the fermentor, which could potentially reduce the ethanol yield. 


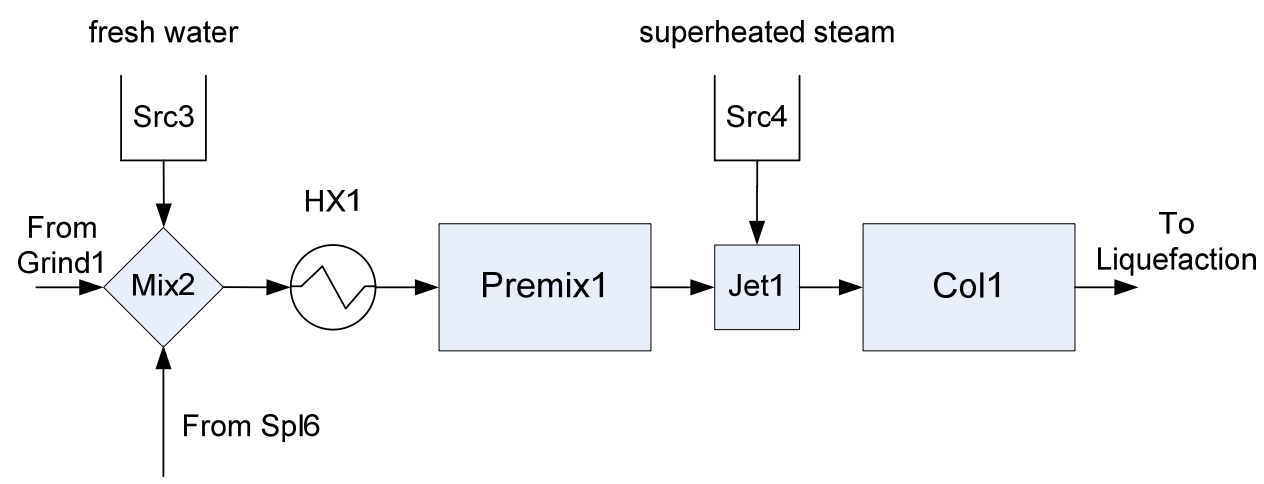

Fig. 4 Continuous corn cooking process

The mass and energy balances for these processes are as follows:

$$
\begin{aligned}
& f c(j, \operatorname{Mix} 2, H X 1)=f c(j, \operatorname{Grind} 1, \operatorname{Mix} 2)+f c(j, \operatorname{Src} 3, \operatorname{Mix} 2)+f c(j, \operatorname{Spl} 6, \operatorname{Mix} 2) \quad \forall j \in J \\
& \sum_{j}(f c(j, \operatorname{Grind} 1, \operatorname{Mix} 2) \cdot C p(j)) \cdot(T(\operatorname{Mix} 2, H X 1)-T(\operatorname{Grind} 1, \operatorname{Mix} 2)) \\
& +\sum_{j}(f c(j, \operatorname{Src} 3, \operatorname{Mix} 2) \cdot C p(j)) \cdot(T(\operatorname{Mix} 2, H X 1)-T(\operatorname{Src} 3, \operatorname{Mix} 2)) \\
& +\sum_{j}(f c(j, \operatorname{Spl6}, \operatorname{Mix} 2) \cdot C p(j)) \cdot(T(\operatorname{Mix} 2, H X 1)-T(\operatorname{Spl6}, \operatorname{Mix} 2))=0 \\
& f c(j, M i x 2, H X 1)=f c(j, H X 1, \text { Premix } 1) \quad \forall j \in J \\
& Q(H X 1)=\sum_{j}(f c(j, M i x 2, H X 1) \cdot C p(j)) \cdot(T(H X 1, \operatorname{Premix} 1)-T(M i x 2, H X 1)) \\
& f c(j, \text { Premix } 1, \text { Jet } 1)=f c(j, H X 1, \text { Premix } 1) \quad \forall j \in J \\
& f c(j, \text { Jet } 1, \text { Col } 1)=f c(j, \text { Premix } 1, \text { Jet } 1)+f c(j, \text { Src } 4, \text { Jet } 1) \quad \forall j \in J \\
& Q(\text { Jet } 1)=f c(\text { water }, \text { Src } 4, \text { Jet } 1) .\left[\begin{array}{c}
C p^{\text {vap }}(\text { water }) .(T(\text { Src } 4, \text { Jet } 1)-T(\text { Jet } 1, \text { Col } 1)) \\
+\Delta H_{v}^{0}(\text { Water }) \cdot\left(\frac{T_{c}(\text { water })-T(\text { Jet } 1, \text { Col } 1)}{T_{c}(\text { water })-T_{b}(\text { water })}\right)^{n_{\text {watson }}}
\end{array}\right] \\
& Q(J e t 1)=\sum_{j} f c(j, \text { Premix } 1, \operatorname{Jet} 1) \cdot C p(j) \cdot(T(J e t 1, \text { Col } 1)-T(\operatorname{Premix} 1, \text { Jet } 1)) \\
& Q(\operatorname{Coll})=\sum_{j} f c(j, J e t 1, \operatorname{Col} 1) \cdot C p(j) \cdot(T(\operatorname{Col} 1, \operatorname{Liq} 1)-T(J e t 1, \operatorname{Col} 1))
\end{aligned}
$$

Here, $C p(j)$ is the specific heat capacity of a component $j$ (in $\mathrm{kJ} / \mathrm{kg}-{ }^{\circ} \mathrm{C}$ ) and is assumed to be constant at a mean value over the given temperature ranges. $T_{c}$ (water) is the critical temperature of water in ${ }^{\circ} \mathrm{C}$, while $T_{b}$ (water) is the normal boiling point of water, $C p^{\text {vap }}$ (water) is the specific heat capacity of water vapor (in $\mathrm{kJ} / \mathrm{kg}^{-}{ }^{\circ} \mathrm{C}$ and assumed to be a constant at a mean value over the given temperature ranges), $\Delta H_{v}^{0}$ (water) is the heat of vaporization of water at its normal boiling point $(\mathrm{kJ} / \mathrm{kg})$. Finally, $n_{\text {watson }}=0.38$, 
in the Watson correlation (see Reid et al., 1987) to calculate enthalpy of vaporization of water at a given temperature.

(iii) Liquefaction and saccharification

Liquefaction and saccharification convert the starch to fermentable sugars. Most yeast strains cannot ferment sugars except glucose and fructose. In this model glucose is considered to be the only fermentable sugar and the possible fermentation of other carbohydrates is neglected. The liquefaction and saccharification operations are shown in Fig. 5.

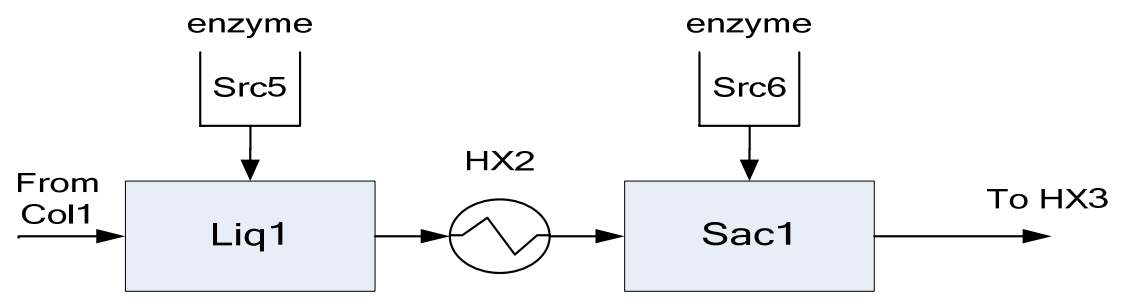

\section{Fig. 5 Liquefaction and saccharification of corn slurry}

The corn mash coming from the vertical column (Coll) is fed to the liquefaction tank (Liq1), where the high temperature tolerant enzyme $\alpha$-amylase is added. The $\mathrm{pH}$ range of liquefaction is 6-6.5 and the temperature is kept at $85^{\circ} \mathrm{C}$ (Jacques et al., 1999). The chemical reaction involved in this step is the hydrolysis of starch to maltose, which involves the use of the endoenzyme $\alpha$-amylase.

$$
2\left(\mathrm{C}_{6} \mathrm{H}_{10} \mathrm{O}_{5}\right)_{n}+n \mathrm{H}_{2} \mathrm{O} \stackrel{\alpha \text {-amylase }}{\longrightarrow} n \mathrm{C}_{12} \mathrm{H}_{22} \mathrm{O}_{11}
$$

This step is followed by the use of the exoenzyme glucoamylase to achieve the conversion of maltose to glucose in the saccharification process (Sac1).

$$
\mathrm{C}_{12} \mathrm{H}_{22} \mathrm{O}_{11}+\mathrm{H}_{2} \mathrm{O} \stackrel{\text { glucoamylase }}{\longrightarrow} 2 \mathrm{C}_{6} \mathrm{H}_{12} \mathrm{O}_{6}
$$

Saccharification operates most efficiently around $75^{\circ} \mathrm{C}$. A heat exchanger $(H X 2)$ cools the mash coming from the liquefaction tank from $85{ }^{\circ} \mathrm{C}$ to $75{ }^{\circ} \mathrm{C}$. The saccharification process is carried out in a $\mathrm{pH}$ range of 4.5-6. The mash is usually acidified by sulfuric acid before adding the glucoamylase into the saccharification vessel. The adjustment of the $\mathrm{pH}$ values is neglected in the process model. Finally, the heats of reaction for both the reactions of starch to maltose, and of maltose to glucose are insignificant and thus neglected in the heat balance. No temperature changes are assumed in the liquefaction and saccharification tanks. 
For the reactions in the liquefaction and saccharification processes, we assume a conversion efficiency of $99 \%$ based on the amount of primary reactant. The reactions are modeled on a mass basis and stoichiometric factors are used in the equations. On a mass basis, the reactions are defined as follows:

$1 \mathrm{~kg}$ starch $+0.0555 \mathrm{~kg}$ water $\stackrel{\alpha \text {-amylase }}{\longrightarrow} 1.0555 \mathrm{~kg}$ maltose

$1 \mathrm{~kg}$ maltose $+0.0526 \mathrm{~kg}$ water $\stackrel{\text { glucoamylase }}{\longrightarrow} 1.0526 \mathrm{~kg}$ glucose

Regarding the enzymes needed in the reactions, the amount of $\alpha$-amylase to be added is $0.05 \% \mathrm{w} / \mathrm{w}$ of the corn mash while the required glucoamylase is $0.12 \% \mathrm{w} / \mathrm{w}$ of the incoming mash (Jacques et al., 1999). In the process model, the enzymes are treated as proteins, and hence they are added to the protein mass of the stream. The effect of the enzymes on the energy balance for both the liquefaction and saccharification units is neglected. The mass and heat balances for this section are as follows:

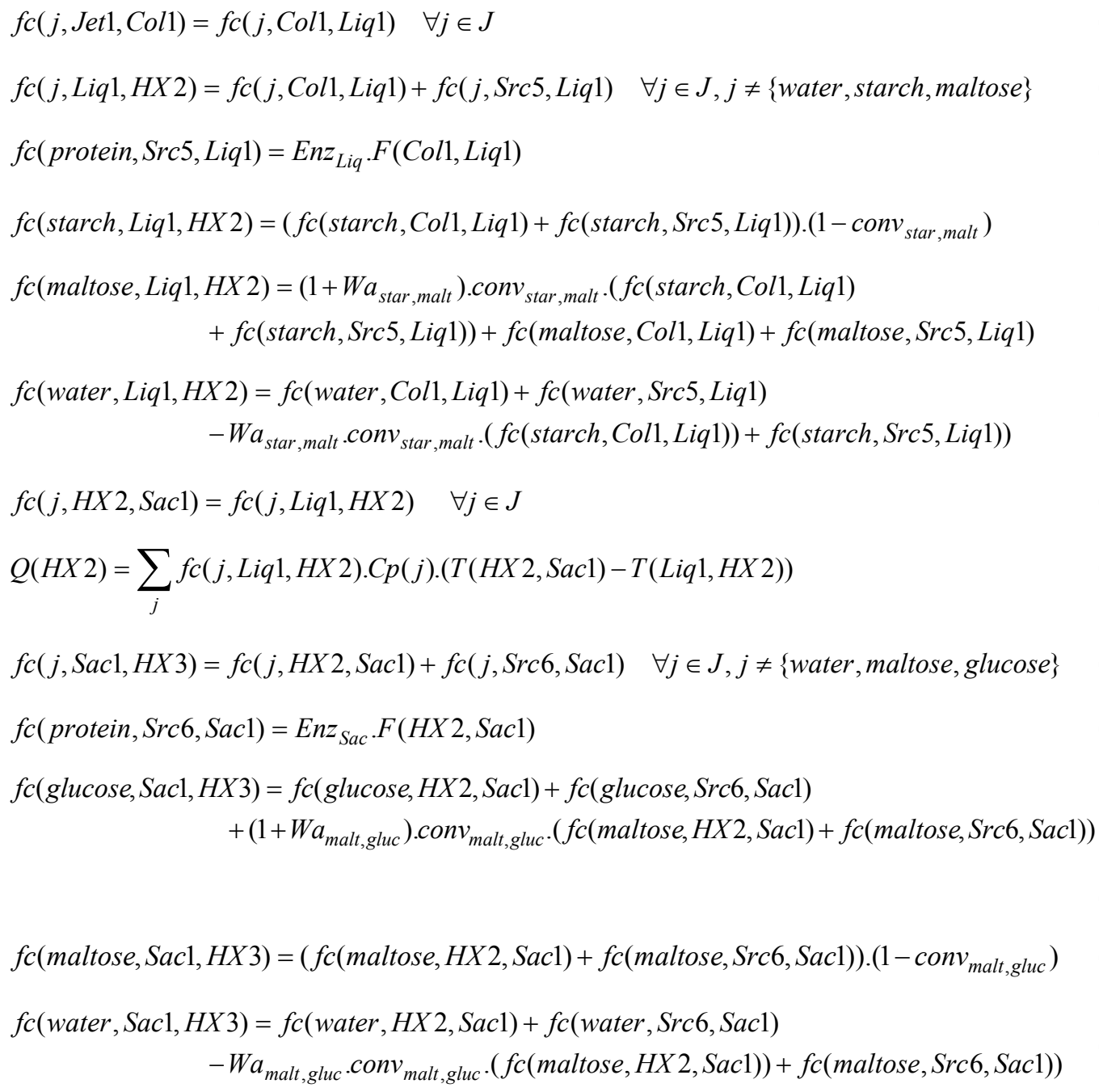




$$
\begin{aligned}
& f c(\text { water, Jet } 1, \text { Col } 1) \geq W a_{\text {abun }} .\left(W a_{\text {star,malt }} \text {.conv }{ }_{\text {star, malt }} . f c(\text { starch, Mix } 2, H X 1)\right. \\
& +W a_{\text {malt }, \text { gluc }} \cdot \text { conv }_{\text {malt }, \text { gluc }} \cdot\left(1+W a_{\text {star, malt }}\right) \cdot f_{c}(\text { starch, Mix 2, HX1)) } \\
& +f c(\text { water }, \operatorname{Src1}, \text { Wash } 1)+f c(\text { water, Spl6, Mix } 2)
\end{aligned}
$$

In the above set of equations, $W a_{\text {star,malt }}=0.0555$ is the amount of water required for hydrolyzing $1 \mathrm{~kg}$ of starch to produce maltose, while $W a_{\text {malt,gluc }}=0.0526$ is the stoichiometric water requirement for converting $1 \mathrm{~kg}$ of maltose into glucose. The terms conv $v_{\text {star,malt }}$ and conv $v_{\text {malt,gluc }}$ stand for the conversion of starch to glucose and the conversion of glucose to maltose, respectively, and are both equal to 0.99. $E n z_{L i q}=$ 0.0005 is the amount of enzymes (in $\mathrm{kg}$ ) required per $\mathrm{kg}$ of corn mash liquefied, while $E n z_{S a c}=0.0012$ is the amount of enzymes (in $\mathrm{kg}$ ) required in the saccharification tank per $\mathrm{kg}$ of corn slurry saccharified. The amount of water needed for the reactions in liquefaction and saccharification is multiplied by a factor $W a_{a b u n}=1.5$ (see eq (30)) to ensure that reactions go to completion, and are not limited by the amount of water present in the mash.

\section{(iv) Fermentation}

The next step in the production of bioethanol is fermentation of the slurry, which is the heart of the process. The corn mash passes from the saccharification tank into a heat exchanger $(H X 3)$ and then into a mixer (Mix3) where the mash is mixed with the yeast, urea and water required for the fermentation. The mass and energy balances for these units are as follows:

$$
\begin{aligned}
& f c(j, H X 3, \operatorname{Mix} 3)=f c(j, \operatorname{Sac} 1, H X 3) \quad \forall j \in J \\
& Q(H X 3)=\sum_{j} f c(j, S a c 1, H X 3) \cdot C p(j) .(T(H X 3, \operatorname{Mix} 3)-T(\operatorname{Sac} 1, H X 3)) \\
& f c(j, \operatorname{Mix} 3, \operatorname{Str} 1)=f c(j, H X 3, \operatorname{Mix} 3)+f c(j, \operatorname{Src} 7, \operatorname{Mix} 3) \quad \forall j \in J \\
& \sum_{j}(f c(j, H X 3, \operatorname{Mix} 3) \cdot C p(j)) \cdot(T(\operatorname{Mix} 3, \operatorname{Str} 1)-T(H X 3, \operatorname{Mix} 3)) \\
& \quad+\sum_{j}(f c(j, \operatorname{Src7}, \operatorname{Mix} 3) \cdot C p(j)) \cdot(T(\operatorname{Mix} 3, \operatorname{Str} 1)-T(\operatorname{Src} 7, \operatorname{Mix} 3))=0
\end{aligned}
$$

Storage tanks (Str1 and Str2) are present at the inlet and outlet of the fermentation tank (Ferl) since the fermentation is a batch process and the processes upstream and downstream of the fermentation are continuous processes. Finally, the temperature of the slurry entering the fermentor must be $32^{\circ} \mathrm{C}$. In this work we have 
assumed for simplicity a single fermentor, although in actual practice such a large fermentor may not be available, and so a train of parallel fermentors are used to carry out the fermentation. The operations in this part of the flowsheet appear in Fig. 6.

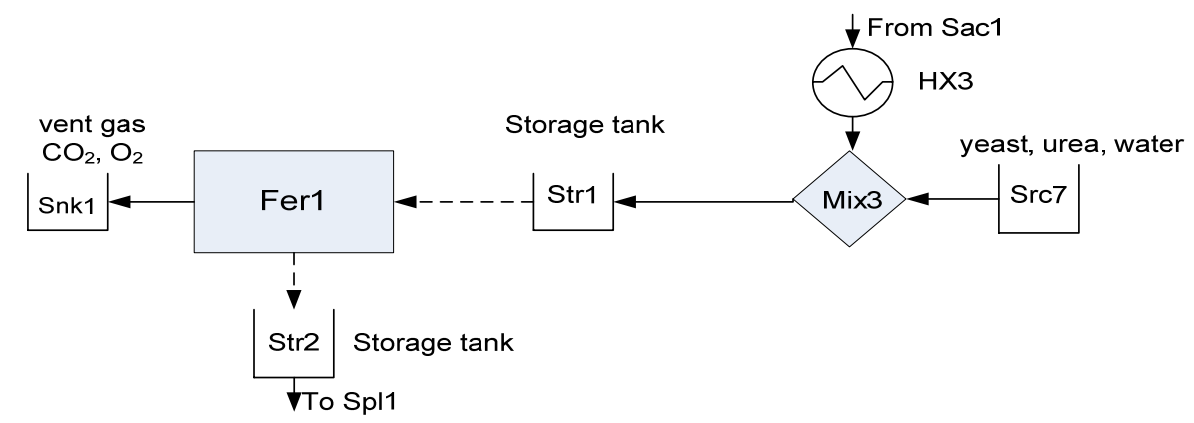

Fig. 6 Fermentation process

The transfer of the reactants into the fermentor, and the transfer of products out from the fermentor are assumed to be instantaneous in the model. The mass transferred into storage tank Str 1 from mixer Mix3, and the mass transferred from the storage tank Str2 to the downstream processes are both assumed to take place over the cycle time $\left(t \_c y c\right)$ over which the fermentation takes place inside the fermentor. Furthermore, it is assumed that no reactions take place inside the storage tanks. We have used storage tanks for a quasi-steady state approximation, although in practice parallel fermentors are used. It is to be noted that we have used a train of parallel fermentors for the cost estimation of the equipment in the plant.

In the fermentor, yeast of the type Saccharomyces cerevisiae is used to convert glucose into ethanol. The most often used form is active dry yeast. The amount of yeast used in the fermentor is a function of the amount of corn feed $\left(2.765 \times 10^{-4} \mathrm{~kg}\right.$ yeast per $\mathrm{kg}$ corn feed processed). More recently, Alper et al. (2006) have engineered a new yeast that is tolerant of higher levels of ethanol and can improve the speed and efficiency of ethanol production. In our work the fermentation is assumed to be carried out for a maximum total time of $30 \mathrm{~h}$. During this time, the first $4 \mathrm{~h}$ are what is known as a lag phase $\left(t_{-} l a g\right)$, when the incubation of yeast takes place and hence there is no conversion of glucose to ethanol. In the remaining $26 \mathrm{~h}$ ( $t_{-}$fer_max), all the glucose gets converted into ethanol and a number of unavoidable by-products. The time dependence of the fermentation reaction will assume a linear conversion of glucose starting after the initial lag phase of $4 \mathrm{~h}$. The total time (or the cycle time) in the fermentor is then given by:

$$
t \_c y c=t \text { lag }+t \text { fer }
$$

where the actual fermentation time is $t f e r \mathrm{~h}$ and is a decision variable. Fig. 7 depicts glucose conversion as a function of time. 


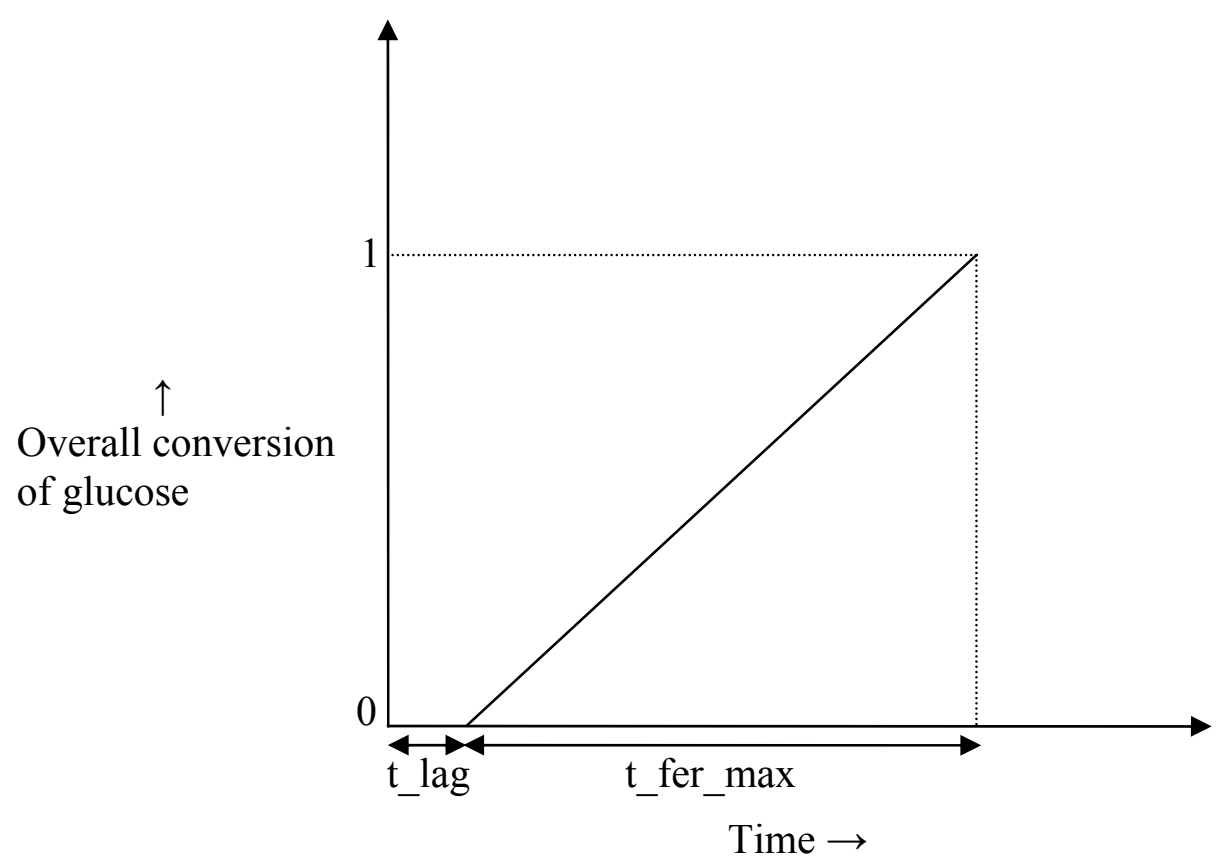

Fig. 7 Conversion of glucose as a function of time

The various products of fermentation and the fraction of glucose that is converted into a particular product appear in Table 1.

Table 1. Fraction of glucose converted to various products during fermentation

\begin{tabular}{|c|c|}
\hline $\begin{array}{c}\text { Product } \\
(\boldsymbol{p})\end{array}$ & $\begin{array}{c}\text { Fraction of glucose that gets converted to } \\
\text { product } \boldsymbol{p} \text { after } \boldsymbol{t} \text { _fer_max } \mathbf{h} \text { of } \\
\text { fermentation time }\left(\zeta_{\text {glucose, }} \boldsymbol{p}\right)\end{array}$ \\
\hline Ethanol & 0.92 \\
\hline Glycerol & 0.034 \\
\hline Succinic acid & 0.01 \\
\hline Lactic acid & 0.002 \\
\hline Acetic acid & 0.0024 \\
\hline Cell mass & 0.0316 \\
\hline
\end{tabular}

All the reactions pertaining to the fermentation are as follows:

1. Glucose to ethanol

glucose $\stackrel{\text { yeast }}{\longrightarrow} 2$ ethanol +2 carbon dioxide

$\mathrm{C}_{6} \mathrm{H}_{12} \mathrm{O}_{6} \stackrel{\text { yeast }}{\longrightarrow} 2 \mathrm{C}_{2} \mathrm{H}_{6} \mathrm{O}+2 \mathrm{CO}_{2}$

$1 \mathrm{~kg}$ glucose $\stackrel{\text { yeast }}{\longrightarrow} 0.5114 \mathrm{~kg}$ ethanol $+0.4885 \mathrm{~kg} \mathrm{CO}$ 
2. Glucose to glycerol

glucose +2 water $\stackrel{\text { yeast }}{\longrightarrow} 2$ glycerol + oxygen

$\mathrm{C}_{6} \mathrm{H}_{12} \mathrm{O}_{6}+2 \mathrm{H}_{2} \mathrm{O} \stackrel{\text { yeast }}{\longrightarrow} 2 \mathrm{C}_{3} \mathrm{H}_{8} \mathrm{O}_{3}+\mathrm{O}_{2}$

$1 \mathrm{~kg}$ glucose $+0.2000 \mathrm{~kg} \mathrm{H} \mathrm{H}_{2} \stackrel{\text { yeast }}{\longrightarrow} 1.0224 \mathrm{~kg}$ glycerol $+0.1776 \mathrm{~kg} \mathrm{O}$

3. Glucose to succinic acid

glucose +2 carbon dioxide $\stackrel{\text { yeast }}{\longrightarrow} 2$ succinic acid + oxygen

$\mathrm{C}_{6} \mathrm{H}_{12} \mathrm{O}_{6}+2 \mathrm{CO}_{2} \stackrel{\text { yeast }}{\longrightarrow} 2 \mathrm{C}_{4} \mathrm{H}_{6} \mathrm{O}_{4}+\mathrm{O}_{2}$

$1 \mathrm{Kg}$ glucose $+0.4885 \mathrm{KgCO}_{2} \stackrel{\text { yeast }}{\longrightarrow} 1.3191 \mathrm{~kg}$ succinic acid $+0.1776 \mathrm{Kg} \mathrm{O}_{2}$

4. Glucose to acetic acid

glucose $\stackrel{\text { yeast }}{\longrightarrow} 3$ acetic acid

$\mathrm{C}_{6} \mathrm{H}_{12} \mathrm{O}_{6} \stackrel{\text { yeast }}{\longrightarrow} 3 \mathrm{C}_{2} \mathrm{H}_{4} \mathrm{O}_{2}$

$1 \mathrm{~kg}$ glucose $\stackrel{\text { yeast }}{\longrightarrow} 1 \mathrm{~kg}$ acetic acid

5. Glucose to lactic acid

glucose $\stackrel{\text { yeast }}{\longrightarrow} 2$ lactic acid

$\mathrm{C}_{6} \mathrm{H}_{12} \mathrm{O}_{6} \stackrel{\text { yeast }}{\longrightarrow} 2 \mathrm{C}_{3} \mathrm{H}_{6} \mathrm{O}_{3}$

$1 \mathrm{~kg}$ glucose $\stackrel{\text { yeast }}{\longrightarrow} 1 \mathrm{~kg}$ lactic acid

6. Glucose to cell mass

glucose +1.2 ammonia $\stackrel{\text { yeast }}{\longrightarrow} 6$ cell mass +2.4 water +0.3 oxygen

$\mathrm{C}_{6} \mathrm{H}_{12} \mathrm{O}_{6}+1.2 \mathrm{NH}_{3} \stackrel{\text { yeast }}{\longrightarrow} 6 \mathrm{CH}_{1.8} \mathrm{O}_{0.5} \mathrm{~N}_{0.2}+2.4 \mathrm{H}_{2} \mathrm{O}+0.3 \mathrm{O}_{2}$

$1 \mathrm{~kg}$ glucose $+0.1135 \mathrm{~kg} \mathrm{NH} \mathrm{H}_{3} \stackrel{\text { yeast }}{\longrightarrow} 0.8202 \mathrm{~kg} \mathrm{cell} \mathrm{mass}+0.2400 \mathrm{~kg} \mathrm{H} \mathrm{H}_{2} \mathrm{O}+0.0533 \mathrm{~kg} \mathrm{O} 2$

In the last reaction, ammonia is one of the reactants. This reaction is indicative of the anaerobic growth of the yeast, where the cell mass of the yeast is increased. The ammonia comes from the following reaction that is also assumed to take place inside the fermentor.

$$
\begin{aligned}
& \text { urea }+ \text { water } \stackrel{\text { urease }}{\longrightarrow} 2 \text { ammonia }+ \text { carbon dioxide } \\
& \mathrm{CO}\left(\mathrm{NH}_{2}\right)_{2}+\mathrm{H}_{2} \mathrm{O} \stackrel{\text { urease }}{\longrightarrow} 2 \mathrm{NH}_{3}+\mathrm{CO}_{2} \\
& 1 \mathrm{~kg} \mathrm{CO}\left(\mathrm{NH}_{2}\right)_{2}+0.2999 \mathrm{~kg} \mathrm{H}_{2} \mathrm{O} \stackrel{\text { urease }}{\longrightarrow} 0.5672 \mathrm{~kg} \mathrm{NH} \mathrm{N}_{3}+0.7327 \mathrm{~kg} \mathrm{CO}_{2}
\end{aligned}
$$

The urea that is required for the reaction is fed into the mixer Mix3, through the source $\operatorname{Src7}$, from where it goes into the storage tank Strl and finally to the fermentor 
Ferl. In order to avoid nitrogen limited growth, we assume that we can feed $10 \%$ more urea than what is stoichiometrically required in the fermentor. Besides sugar and nitrogen, other nutrients such as oxygen, and minerals and vitamins are also necessary for efficient fermentation of glucose to ethanol, although in the model the effect of these nutrients is neglected.

In order to model the conversion of glucose to various products $p \in P=$ \{ethanol, glycerol, succinic acid, lactic acid, acetic acid, cell mass $\}$ on a mass basis, we make use of the parameter $\zeta_{\text {glucose }, p}$ and the respective stoichiometric coefficients on a mass basis, and calculate a parameter $\operatorname{conv}(p)$. An example calculation of $\operatorname{conv}(p)$ for ethanol yields a value of $0.92 * 0.5114=0.47$

The variable conv $t(p)$ is dependent on the actual time of fermentation and is defined for all the considered products of the fermentation as follows:

$$
c o n v_{-} t(p)=\operatorname{conv}(p) \cdot \frac{t \text { fer }}{t \text { fer_max }}
$$

For example, conv_t(ethanol) is defined as:

$$
\text { conv_t }(\text { ethanol })=0.92 \cdot 0.5114 \cdot \frac{t_{-} \text {fer }}{t_{-} \text {fer_max }}=0.47 \cdot \frac{t_{-} \text {fer }}{t_{-} \text {fer_max }}
$$

The conversion factors for all fermentation products on a mass basis are summarized in Table 2.

\section{Table 2. Conversion factors for different products on a mass basis}

\begin{tabular}{|c|c|}
\hline Product (p) & $\boldsymbol{c o n v}(\boldsymbol{p})$ \\
\hline Ethanol & 0.47 \\
\hline Glycerol & 0.034 \\
\hline Succinic acid & 0.013 \\
\hline Lactic acid & 0.002 \\
\hline Acetic acid & 0.0024 \\
\hline Cell mass & 0.026 \\
\hline
\end{tabular}

The mass of a component $j$ entering the fermentor $\left(m_{-} i n(j)\right)$ is dependent on the cycle time $\left(t_{-} c y c\right)$ and also the flow of component $j$ in the stream from mixer Mix 3 to storage tank Str1, and is given by the following equation:

$$
m_{-} \operatorname{in}(j)=f c(j, \operatorname{Mix} 3, \operatorname{Str} 1) .\left(t_{-} c y c\right) .3600 \quad \forall j \in J
$$

For the case of urea, the input mass is 1.1 times that required to produce sufficient amount of ammonia that will react with an unit mass of glucose and result in the growth of yeast. It is modeled with eq (38). 
$m_{-}$in $($urea $)=0.006955 \cdot \frac{t_{-} f e r}{t_{-} f e r_{-} \max } \cdot m_{-}$in $($glucose $)$

The masses of select products produced at the end of the fermentation cycle $\left(m \_\right.$out $\left.(j)\right)$ is a function of the conversion of glucose to these products and the amount of glucose that is input into the fermentor (eq (39)).

$$
\begin{aligned}
m_{-} \text {out }(j)=m_{-} & \text {in }(j)+\text { conv_t } t(j) . m_{-} \text {in }(\text { glucose }) \\
j & =\{\text { ethanol, glycerol, succinic acid, lactic acid, acetic acid, cell mass }\}
\end{aligned}
$$

For other products and the reactants, the outlet mass is computed using the following set of equations (eq (40)-eq (45)).

$$
\begin{aligned}
& m_{-} \text {out }(p)=m_{-} \text {in }(p) \\
& p=\{\text { starch, maltose, protein, cellulose, hemicellulose, oil }, \text { ash }\} \\
& m_{-} \text {out }(\text { glucose })=\left(1-\frac{t_{-} f e r}{t_{-} f e r \_\max }\right) \cdot m_{-} \text {in }(\text { glucose }) \\
& m_{-} \text {out }(\text { urea })=\left(\frac{0.1}{1.1}\right) \cdot m_{-} \text {in }(\text { urea }) \\
& m_{-} \text {out }(\text { water })=m_{-} \text {in }(\text { water })-0.00111 \cdot \frac{t_{-} f e r}{t_{-} f e r_{-} \max } \cdot m_{-} \text {in }(\text { glucose }) \\
& m_{-} \text {out }(\text { carbon dioxide })=m_{-} \text {in }(\text { carbon dioxide })+0.449 \cdot \frac{t_{-} f e r}{t_{-} f e r_{-} \max } \cdot m_{-} \text {in }(\text { glucose }) \\
& m_{-} \text {out }(\text { oxygen })=m_{-} \text {in }(\text { oxygen })+0.00949 \cdot \frac{t_{-} f e r}{t_{-} f e r_{-} \max } \cdot m_{-} \text {in }(\text { glucose })
\end{aligned}
$$

The carbon dioxide and oxygen that are produced are assumed to be constantly vented out to a sink (Snk1) from where they can be sequestered, and hence the flowrate of these gases from the fermentor is calculated using eqs (46) and (47).

$$
\begin{aligned}
& m_{-} \text {out }(\text { carbon dioxide })=f c(\text { carbon dioxide, Fer } 1, \text { Snk } 1) .\left(t \_c y c\right) .3600 \\
& m \text { _out }(\text { oxygen })=f c(\text { oxygen }, F e r 1, S n k 1) .\left(t \_c y c\right) .3600
\end{aligned}
$$

The slurry from the fermentor contains a number of new components and is sent to a storage tank (Str2). The flowrate of the components in the solid-liquid mixture is determined from eq (48).

$$
m_{-} \text {out }(j)=f c(j, S t r 2, S p l 1) .\left(t_{-} c y c\right) .3600 \quad \forall j \in J, j \neq\{\text { carbon dioxide, oxygen }\}
$$

Further, the fermentation of glucose to ethanol by yeast is an exothermic reaction. Therefore, heat $(Q(F e r l))$ must be removed in order to keep the temperature in the fermentor constant at the recommended value of $32{ }^{\circ} \mathrm{C}$. This heat has to be removed over the growth phase of the yeast. Since a linear conversion of glucose during the fermentation time is assumed, this heat must be removed continuously during the 
fermentation time. During the lag phase no heat has to be removed. The simplified heat balance for the fermentor gives rise to the following equation:

$$
Q(F e r 1) . t_{-} \text {fer. } 3600=-808.7 .\left(m_{-} \text {out }(\text { etho })-m_{-} \text {in }(\text { etho })\right)
$$

For removing the heat produced in the fermentors, internal cooling coils, internal cooling panels, external cooling jacket or heat exchangers with recirculation are commonly used.

Yeast stress factors, including bacterial infection, high temperatures, high alcohol levels, and high acid levels inhibit ethanol production. Bacterial infection will reduce the ethanol yield drastically as the bacteria compete with the yeast for the substrates. Bacteria under anaerobic conditions also produce relatively large amounts of acetic and lactic acid, which further stress the yeast (Jacques et al., 1999). Ethanol in too high concentration is also toxic for the yeast. The recommended temperature for fermentation for $\mathrm{S}$. cerevisiae is between $30-35^{\circ} \mathrm{C}$. If the temperature rises or falls too much, the yeast will produce less ethanol and more of other by-products. Furthermore, higher temperature favors bacterial growth.

Ethanol content over $23 \%-\mathrm{v} / \mathrm{v}$, lactic acid content over $0.8 \%-\mathrm{w} / \mathrm{v}$, acetic acid content over $0.05 \%-\mathrm{w} / \mathrm{v}$, and an initial glucose content over $38 \%-\mathrm{w} / \mathrm{v}$ are the inhibitory levels of these components (see Jacques et al., 1999). These inhibitory levels are converted to mass fractions (see Table 3 ) in order to use them as bounds on the mass fraction of the above mentioned inhibitors in the process model.

Table 3. Inhibitory levels (mass fractions) of various components inside the fermentor

\begin{tabular}{|c|c|}
\hline Component & Critical mass fraction \\
\hline glucose & 0.21 \\
\hline ethanol & 0.16 \\
\hline lactic acid & 0.0089 \\
\hline acetic acid & 0.00055 \\
\hline succinic acid & 0.0033 \\
\hline solids & 0.36 \\
\hline
\end{tabular}

Also, the amount of solids must be limited to about $36 \%$ in the fermentor. This is enforced by the following equations: 


$$
\begin{aligned}
& \quad \sum_{\begin{array}{l}
j=\text { starch, protein } \\
\text { cell mass, cellulose } \\
\text { hemicellulose, ash }
\end{array}} x(j, \text { Mix } 3, \text { Str } 1) \leq \text { solids }^{\max } \\
& \qquad \sum_{\begin{array}{l}
j=\text { starch, protein } \\
\text { cell mass,cellulose } \\
\text { hemicellulose, ash }
\end{array}} x(j, \text { Str } 2, \text { Spl } 1) \leq \text { solids }
\end{aligned}
$$

\section{Solid liquid separation}

The slurry coming out of the fermentor has to be separated into a liquid (ethanol + water mixture + solubles) and solid component. The solid-liquid separation can either be achieved by a centrifuge, or by a mechanical press, or by a distillation column known as a beer column. Since a centrifuge and a mechanical press do the same separation job, only one separation technology is investigated for this separation task. The maintenance cost and power requirements of a centrifuge are usually higher compared to a mechanical press, and hence a mechanical press is considered in the work. In case the solids are separated from the liquids prior to the beer column, the column can be designed as a regular distillation column. If no mechanical separation equipment is used in front of the column, the beer column must be designed for a heavy solid load. In this case the investment cost for the beer column is higher.

In terms of the flowsheet, if a mechanical press is used before the beer column, the flows 'Spl1' $\rightarrow$ 'HX4', 'Spl3' $\rightarrow$ 'HX12' do not exist (see Fig. 2). In case the mechanical separator is used after the beer column, the flows 'Spl1' $\rightarrow$ 'MecP1', 'Spl3' $\rightarrow$ 'HX11' are eliminated. Mathematically, this can be represented as a disjunction, although this representation was not considered in this work and we solved two cases, one with the solid-liquid separation before the beer column, and one with the solidliquid separation after the beer column, to determine the optimal design. Note that a recycle stream must be included from the dryer (Dryl) to the beer column $(B C 1)$. Since the solid outlet of the mechanical press is assumed to have a moisture content of about $40 \%$, some ethanol also remains in the solid phase, and thus it is necessary to have a recycle stream to recover this ethanol.

The slurry coming out of the fermentor is sent to storage tank Str2, from where it is sent to splitter Spll and the flow balance is modeled as follows:

$f_{c}(j, \operatorname{Str} 2, \operatorname{Spl} 1)=f_{c}(j, \operatorname{Spl} 1, H X 4)+f_{c}(j, \operatorname{Spl} 1, M e c P 1) \quad \forall j \in J, j \neq\{$ carbon dioxide, oxygen $\}$ 
A distillation system separates the ethanol from water in the liquid mixture. The beer column separates most of the ethanol from water (and solids, if any) and produces a top stream rich in ethanol, and a bottom stream rich in water, as shown in Fig. 8.

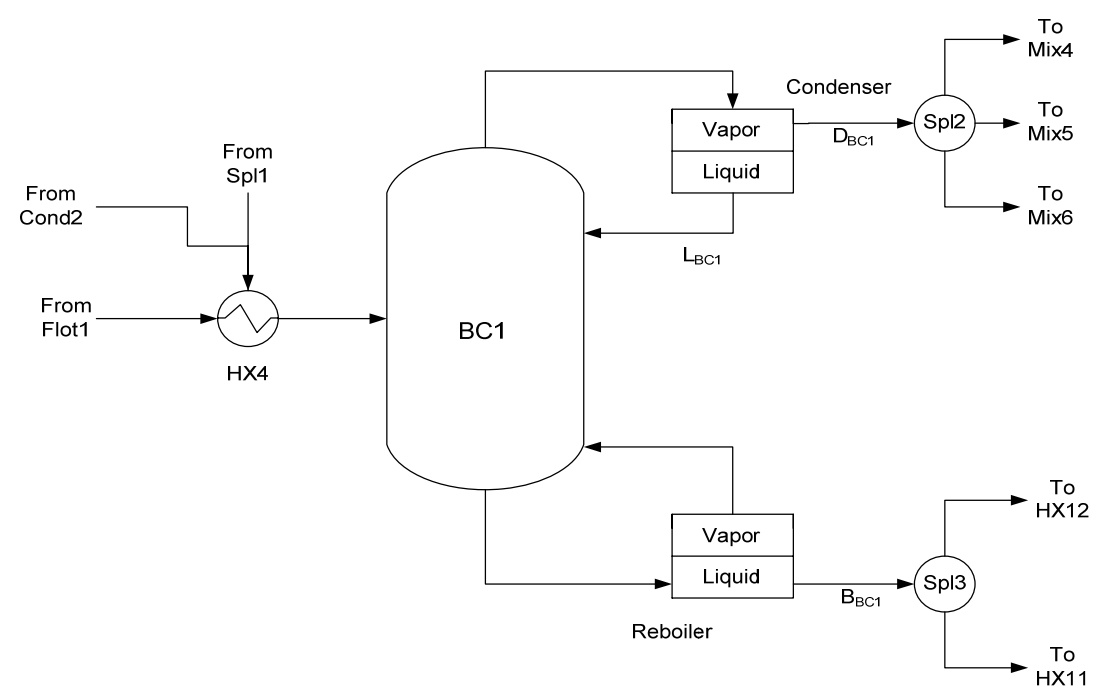

Fig. 8 Beer column

The beer column serves to reduce the overall flowrate for the ethanol purification downstream. This column usually has a large diameter, but only few trays. The inlet stream to the beer column $(B C 1)$ is pre-heated in a heat exchanger $(H X 4)$ to its bubble point. This heat exchanger has three possible inlet streams (see Fig. 2):

1. The fermentor outlet stream from splitter Spll to heat exchanger $H X 4$

2. The stream from splitter $\mathrm{Spl7}$ to heat exchanger $H X 4$

3. The stream from flotation unit Flot 1 to heat exchanger $H X 4$

The flow and energy balances for this heat exchanger are given below.

$f c(j, H X 4, B C 1)=f c(j, S p l 1, H X 4)+f c(j, F l o t 1, H X 4)+f c(j, \operatorname{Spl} 7, H X 4) \quad \forall j \in J, j \neq\{$ carbon dioxide, oxygen $\}$

$$
\begin{aligned}
& Q(H X 4)=\sum_{\substack{j \\
j \neq\{\text { carbon dioxide, oxygen }\}}} f c(j, S p l 1, H X 4) \cdot C p(j) \cdot(T(H X 4, B C 1)-T(S p l 1, H X 4)) \\
& +\sum_{j \neq\{\text { carbon dioxide, oxygen }\}} f c(j, F l o t 1, H X 4) \cdot C p(j) \cdot(T(H X 4, B C 1)-T(F l o t 1, H X 4)) \\
& +\sum_{\substack{j \\
j \neq\{\text { carbon dioxide, oxygen }\}}} f c(j, S p l 7, H X 4) \cdot C p(j) \cdot(T(H X 4, B C 1)-T(\operatorname{Spl7}, H X 4))
\end{aligned}
$$

The recovery of ethanol in the distillation columns in the plant is fixed to be $99.6 \%$ to reduce ethanol losses. In order to have operational flexibility in the beer 
column, the recovery of water at the top is a treated as a variable. The flow balances are easily formulated in terms of these recoveries.

$$
\begin{aligned}
& f c(j, H X 4, B C 1)=f c(j, B C 1, S p l 2)+f c(j, B C 1, S p l 3) \quad \forall j \in J, j \neq\{\text { carbon dioxide, oxygen }\} \\
& f_{c}(\text { Water }, B C 1, S p l 2)=r e c_{\text {water }}(B C 1) . f c(\text { Water }, H X 4, B C 1) \\
& f_{c}(\text { Ethanol, BC1,Spl2 })=\operatorname{rec}_{\text {ethanol }}(B C 1) . f_{c}(\text { Ethanol, } H X 4, B C 1)
\end{aligned}
$$

In the above equations $\operatorname{rec}_{\text {water }}(B C 1)$ is the recovery of water in the beer column $B C 1$ while rec $_{\text {ethanol }}(B C 1)$ stands for the recovery of ethanol in the beer column $B C 1$.

The theoretical number of trays in the beer column, $n_{\text {theo }}(B C 1)$, can be derived from the Fenske equation (Biegler et al., 1999) with ethanol as the light key component and water as the heavy key component. With a tray efficiency of 0.8 , the actual number of plates in the beer column ( $\left.n_{\text {actual }}(B C 1)\right)$ can also be computed.

$$
\begin{aligned}
& n_{\text {theo }}(B C 1)=\frac{\ln \left(\frac{r e c_{\text {ethanol }}(B C 1) .\left(1-r e c_{\text {water }}(B C 1)\right)}{r e c_{\text {water }}(B C 1) .\left(1-r e c_{\text {ethanol }}(B C 1)\right.}\right)}{\ln \left(\alpha_{\text {ethanol } / \text { water }}\right)} \\
& n_{\text {actual }}(B C 1)=\frac{n_{\text {theo }}(B C 1)-1}{0.8}
\end{aligned}
$$

The relative volatility of ethanol with respect to water $\left(\alpha_{\text {ethanol } / \text { water }}\right)$ is taken to be 2.2389 and is assumed to be constant over the temperature range of the column. Calculating the relative volatilities of the corn oil, glycerol, and the acids leads to negligibly small relative volatilities. Therefore, water is chosen to be the heavy key and ethanol the light key for the calculations in both the beer column as well as the rectification column. Since all components except ethanol are heavier than water, they are all assumed to go into the bottom outlet. Hence, the effect of all components except water and ethanol on the condenser temperature is neglected. Further, only ethanol and water are assumed to be present in the vapor distillate stream coming out from the condenser of the beer column, and so only these components are considered to be present in the ethanol purification section. A partial condenser is used in the beer column to obtain a vapor distillate since the molecular sieves and the corn grit adsorption bed present in the ethanol purification section handle vapor mixtures of ethanol and water. In the feed to the beer column and in the reboiler, the effect of these components other than water on the bubble point is negligible, since their relative volatilities are extremely small and their mole fractions are also very small. The vapor pressures of water and ethanol are predicted by the Antoine equation. The beer column 
operates at atmospheric pressure $\left(P_{B C 1}=1 \mathrm{~atm}\right)$. A pressure drop of $0.1 \mathrm{~atm}$ across the beer column $\left(\Delta P_{B C 1}\right)$ is assumed. Therefore, the temperature of the inlet stream is calculated at $1 \mathrm{~atm}$, the temperature of the reboiler is computed at $1.05 \mathrm{~atm}$ and the temperature in the condenser is calculated at $0.95 \mathrm{~atm}$.

The dew point equation (DPE) given by Biegler et al. (1999) is used to relate the temperature inside the condenser with the mass fractions of the vapor distillate and the refluxed liquid. A reflux ratio $\left(R_{B C 1}\right)$ of 2 is taken for the beer column.

$$
p_{n}^{0}(T)=P_{t o t} \sum_{k} \frac{y_{k}}{\alpha_{k / n}}
$$

In eq (DPE), $n$ stands for the most abundant component (in the condenser of the beer column it is ethanol), $k$ is the set of all components in the mixture (ethanol and water), $\alpha_{k / n}$ is the relative volatility of $k$ with respect to $n, y_{k}$ is the mole fraction of component $k$ in the vapor, $P_{t o t}$ is the total pressure of the vapor, and $p_{n}^{0}(T)$ is the vapor pressure of component $n$ at temperature $T$.

Written in terms of column pressure and pressure drop, the dew point equation for the beer column condenser becomes

$$
p_{\text {ethanol }}^{0}(T)=\left(P_{B C 1}-\frac{\Delta P_{B C 1}}{2}\right) \cdot\left(y_{\text {ethanol }}+y_{\text {water }} \cdot \alpha_{\text {ethanol } / \text { water }}\right)
$$

Combining this with the Antoine equation yields the following set of equations for the beer column condenser,

$$
\begin{aligned}
& m f(j, B C 1, S p l 2) . \sum_{h=\{\text { ethanol,water }\}} \frac{x(h, B C 1, S p l 2)}{M W_{h}}=\frac{x(j, B C 1, S p l 2)}{M W_{j}} \quad j=\{\text { ethanol, water }\} \\
& \exp \left(A_{\text {ethanol }}-\frac{B_{\text {ethanol }}}{T(B C 1, S p l 2)+C_{\text {ethanol }}}\right)=\left(P_{B C 1}-\frac{\Delta P_{B C 1}}{2}\right) .\left(m f(\text { water, BC1,Spl }) . \alpha_{\text {ethanol water }}+m f(\text { ethanol } B C 1, S p l 2)\right)
\end{aligned}
$$

Here $m f(j, B C 1, S p l 2)$ is the mole fraction of component $j$ in the distillate drawn from the top of the beer column and $M W_{j}$ is the molecular weight of component $j$.

Since a partial condenser is used in the beer column, the composition of the condensed liquid is not the same as the top product, which is removed as saturated vapor. It is assumed that the extracted vapor is in equilibrium with the condensed phase. The composition of the refluxed stream can be calculated by using the vapor-liquid equilibrium relationship for water and ethanol at the temperature of the condenser. The vapor-liquid equilibrium for an assumed ideal liquid mixture is given by the following relationship: 


$$
m_{k}=\frac{y_{k} P_{t o t}}{p_{k}^{0}(T)}
$$

Here, $m_{k}$ is the mole fraction of component $k$ in the liquid mixture, while $y_{k}$ is the mole fraction of component $k$ in the vapor that is in equilibrium with the liquid. $P_{t o t}$ is the total pressure of the vapor, while $p_{k}^{0}(T)$ is the vapor pressure of component $k$ at temperature $T$.

The equilibrium relation for the vapor and liquid in the beer column condenser, along with ideal solution assumptions inside the condenser yield the following model equations:

$$
\begin{aligned}
& l f_{B C 1}(\text { ethanol })=\frac{m f(\text { ethanol, } B C 1, S p l 2) \cdot\left(P_{B C 1}-\frac{\Delta P_{B C 1}}{2}\right)}{\exp \left(A_{\text {ethanol }}-\frac{B_{\text {ethanol }}}{T(B C 1, S p l 2)+C_{\text {ethanol }}}\right)} \\
& l f_{B C 1}(\text { water })=1-l f_{B C 1}(\text { ethanol }) \\
& x f_{B C 1}(j) . \sum_{h=\{\text { ethanol, water }\}} l f_{B C 1}(h) \cdot M W_{h}=l f_{B C 1}(j) \cdot M W_{j} \quad j=\{\text { ethanol, water }\}
\end{aligned}
$$

Finally, the cooling heat load required for the condenser is given by eq (65).

$$
Q_{-} \operatorname{cond}(B C 1)=-F(B C 1, S p l 2) \cdot R_{B C 1} \cdot \sum_{h=\{\text { ethanol, water }\}} x f_{B C 1}(h) \cdot \Delta H_{v}^{0}(h) \cdot\left(\frac{T_{c}(h)-T(B C 1, S p l 2)}{T_{c}(h)-T_{b}(h)}\right)^{n_{\text {watson }}}
$$

In the above equations, $l f_{B C 1}(j)$ is the mole fraction and $x f_{B C 1}(j)$ is the mass fraction of component $j$ in the liquid refluxed from the condenser of the beer column $B C l$, and $\Delta H_{v}^{0}(h)$ is the heat of vaporization of component $h$ at its normal boiling point. $T_{c}(h)$ and $T_{b}(h)$ are the critical temperature and the normal boiling temperature of component $h$, respectively.

The bubble point equation (BPE) is used to calculate the inlet temperature and the reboiler temperature for the beer column. The (BPE) is given by Biegler et al. (1999).

$$
P_{t o t}=\frac{\bar{\alpha}}{\alpha_{k / n}} p_{k}^{0}(T)
$$

where, $\bar{\alpha}=\sum_{i} \alpha_{i / n} \cdot m_{i}$ 
In the above equation, $k$ stands for the most abundant component (in the reboiler of the beer column it is water), $n$ is water, $\alpha_{k / n}$ is the relative volatility of $k$ with respect to $n, m_{i}$ is the mole fraction of component $i$ in the liquid, $P_{t o t}$ is the total pressure of the vapor, and $p_{k}^{0}(T)$ is the vapor pressure of component $k$ at temperature $T$.

This leads to the following equations (eqs (66)-(69)).

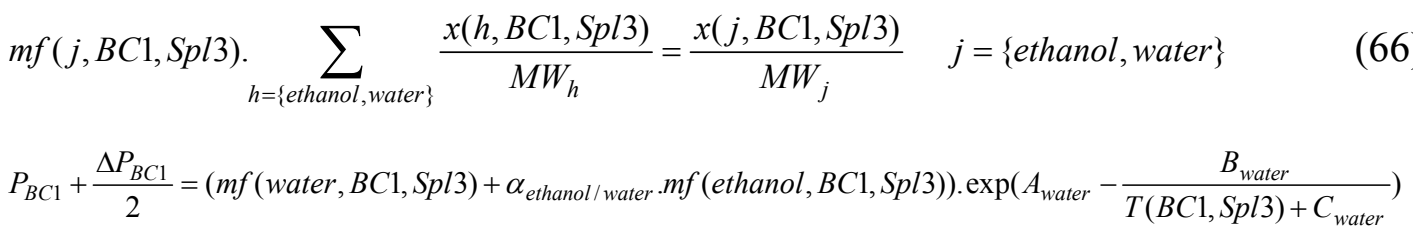

$m f(j, H X 4, B C 1) . \sum_{h=\{\text { ethanol,water }\}} \frac{x(h, H X 4, B C 1)}{M W_{h}}=\frac{x(j, H X 4, B C 1)}{M W_{j}} \quad j=\{$ ethanol, water $\}$

$P_{B C 1}=\left(m f(\right.$ water $, H X 4, B C 1)+\alpha_{\text {ethanol } \text { water }} \cdot m f($ ethanol, $\left.H X 4, B C 1)\right) \cdot \exp \left(A_{\text {water }}-\frac{B_{\text {water }}}{T(H X 4, B C 1)+C_{\text {water }}}\right)$

Since the recovery of ethanol at the top is fixed at $99.6 \%$, the bottom stream contains almost no ethanol. The relative volatilities of other species with respect to water are very small, so their contributions to the heat of vaporization in the reboiler may be neglected. Neglecting also the temperature change in the reboiler, the heat balance reduces to:

$$
Q_{-} r e b(B C 1)=F(B C 1, S p l 2) .\left(1+R_{B C 1}\right) . \Delta H_{v}^{0}(\text { Water }) \cdot\left(\frac{T_{c}(\text { Water })-T(B C 1, S p l 3)}{T_{c}(\text { Water })-T_{b}(\text { Water })}\right)^{n_{\text {watson }}}
$$

Finally, to avoid a beer column with many separation trays, the mass fraction of ethanol in the vapor distillate from the condenser of the beer column is bounded to be less than 0.72 .

The top product from the beer column is assumed to consist of only ethanol and water and the vapor mixture of these components is sent to splitter Spl2 (see Fig. 2), which is modeled as follows:

$F(B C 1, \operatorname{Spl2})=F(\operatorname{Spl2,Mix} 4)+F(\operatorname{Spl2}, \operatorname{Mix} 5)+F(\operatorname{Spl2}, \operatorname{Mix} 6)$ 
$x(j$, Spl2,Mix 4$)=x(j, B C 1$, Spl2 $) \quad j=\{$ ethanol, water $\}$

$x(j, \operatorname{Spl} 2$, Mix 5$)=x(j, B C 1$, Spl2 $) \quad j=\{$ ethanol, water $\}$

$x(j, \operatorname{Spl2}$, Mix 6$)=x(j, B C 1$, Spl $) \quad j=\{$ ethanol, water $\}$

$T(\operatorname{Spl2}, \operatorname{Mix} 4)=T(B C 1, \operatorname{Spl})$

$T(\operatorname{Spl2,Mix} 5)=T(B C 1, S p l 2)$

$T(\operatorname{Spl} 2, \operatorname{Mix} 6)=T(B C 1, S p l 2)$

The liquid stream at the bottoms of the beer column is sent to splitter $\mathrm{Spl3}$ from where it can be sent to different units. The following equations describe this splitter:

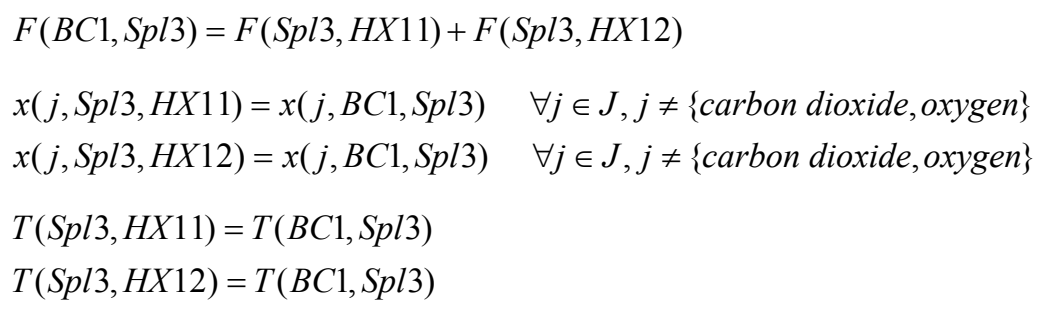

\section{Purification of ethanol to fuel grade}

There are several technologies available to separate ethanol from water. In this context, a common rectification tower working at atmospheric pressure, a bed of corn grits, and/ or molecular sieves can be used. It should be noted that pervaporation is another alternative separation scheme (Ikegami et al., 2003), but this was not considered in this work. The ethanol-water vapor mixture obtained at the top of the beer column can be sent to any of these purifying options. The separation technologies are interconnected to each other as can be seen from the superstructure in Fig. 2. From the superstructure, it can also be seen that a combination of these technologies can be used and so no discrete decisions are involved in the model. The purified ethanol vapor obtained from these processes is collected and condensed for storage.

(vi) Rectification

Rectification uses a distillation column to produce nearly azeotropic ethanol. It is assumed that the feed to the rectification column (Recl) consists of ethanol and water only. The feed for the rectification is in vapor form and comes from different streams mixed in the mixer unit Mix4. The rectification process appears in Fig. 9. 


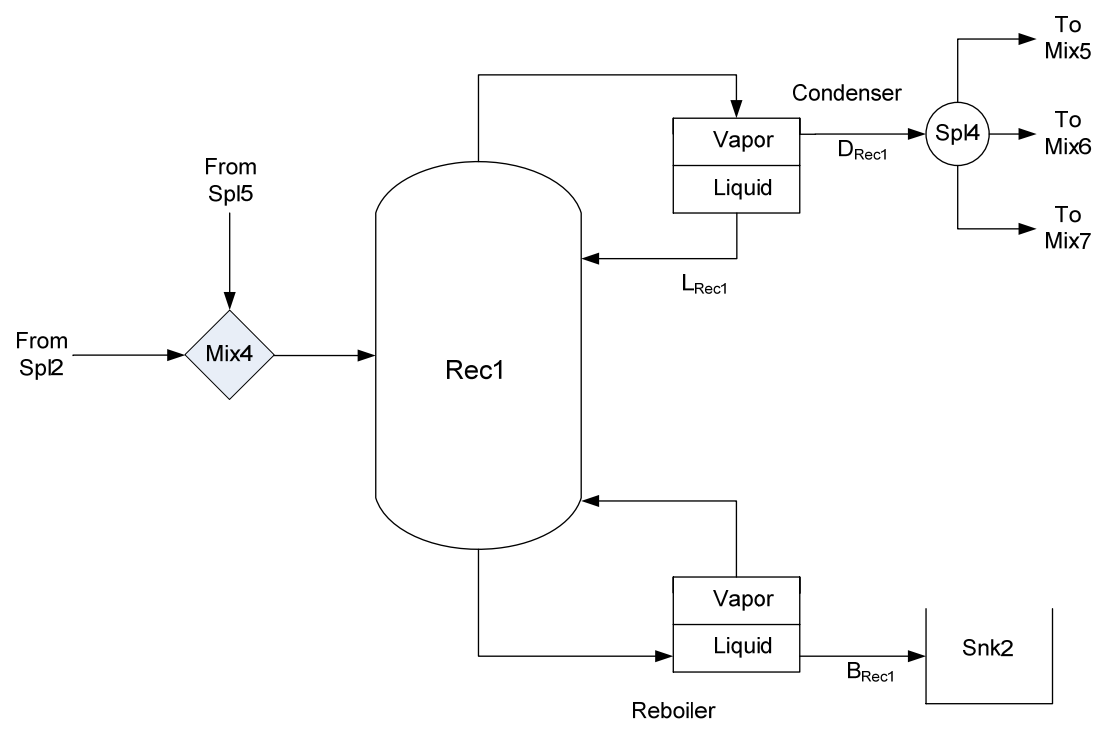

Fig. 9 Rectification column

Since the azeotropic composition of an ethanol-water mixture at atmospheric pressure is about $95 \mathrm{wt} \%$ of ethanol, this is the maximum achievable purity of ethanol in an atmospheric rectification column. The required purity for fuel grade ethanol is higher, so the mixture must be purified further. The rectifier column is modeled in a similar fashion as the beer column. A partial condenser and reboiler are used in this unit. These parts are modeled in the same way they are for the beer column. The pressure drop in the column and the tray efficiencies are assumed to be the same as those for the beer column. Again, the ethanol recovery is fixed to $99.6 \%$ and the recovery of water at the top of the column is selected to be a variable. The composition of the condensate in the condenser of this column is calculated by assuming equilibrium between the vapor outlet and the liquid reflux stream. The condenser temperature is determined by the dew point equation for the top outlet composition. Furthermore, it is assumed that only water is vaporized in the reboiler and the temperature of the reboiler is calculated using the bubble point equation for the bottom outlet composition. The following set of equations are used to model the rectifier.

$$
\begin{aligned}
& f_{c}(h, \operatorname{Mix} 4, \operatorname{Rec} 1)=f_{c}(h, S p l 2, \operatorname{Mix} 4)+f c(h, S p l 5, \text { Mix } 4) \quad h=\{\text { ethanol }, \text { water }\} \\
& \sum_{h=\{\text { ethanol,water }\}}\left(f c(h, S p l 2, M i x 4) \cdot C p^{v a p}(h)\right) .(T(M i x 4, \operatorname{Rec} 1)-T(\operatorname{Spl} 2, \operatorname{Mix} 4)) \\
& +\sum_{h=(e \text { thanol,water }\}}\left(f c(h, S p l 5, \operatorname{Mix} 4) \cdot C p^{v a p}(h)\right) \cdot(T(\operatorname{Mix} 4, \operatorname{Rec} 1)-T(\operatorname{Spl} 5, \operatorname{Mix} 4))=0 \\
& f_{c}(h, M i x 4, \operatorname{Re} c 1)=f_{c}(h, \operatorname{Re} c 1, \operatorname{Spl} 4)+f_{c}(h, \operatorname{Re} c 1, \operatorname{Snk} 2) \quad h=\{\text { ethanol, water }\} \\
& f_{c}(\text { Water }, \operatorname{Re} c 1, \operatorname{Spl} 4)=r e c_{\text {water }}(\operatorname{Re} c 1) . f_{c}(\text { Water }, \text { Mix } 4, \operatorname{Re} c 1)
\end{aligned}
$$


$f c($ Ethanol $, \operatorname{Re} c 1, \operatorname{Spl} 4)=\operatorname{rec}_{\text {ethanol }}(\operatorname{Re} c 1) \cdot f c($ Ethanol, Mix $4, \operatorname{Re} c 1)$

In the above equations, $\operatorname{rec}_{\text {water }}(\operatorname{Rec} 1)$ is the recovery of water in the rectification column Recl while $\operatorname{rec}_{\text {ethanol }}(\operatorname{Rec} 1)$ stands for the recovery of ethanol in the rectification column Rec1.

The theoretical number of stages in the rectification column, $n_{\text {theo }}(\operatorname{Rec} 1)$, can be derived from the Fenske equation with ethanol as the light key component and water as the heavy key component. With a tray efficiency of 0.8 , the actual number of plates in the rectification column ( $\left.n_{\text {actual }}(\operatorname{Rec} 1)\right)$ can also be estimated as follows:

$$
\begin{aligned}
& n_{\text {theo }}(\operatorname{Rec} 1)=\frac{\ln \left(\frac{r e c_{\text {ethanol }}(\operatorname{Rec} 1) .\left(1-r e c_{\text {water }}(\operatorname{Rec} 1)\right)}{\operatorname{rec}_{\text {water }}(\operatorname{Rec} 1) .\left(1-r e c_{\text {ethanol }}(\operatorname{Rec} 1)\right.}\right)}{\ln \left(\alpha_{\text {ethanol } / \text { water }}\right)} \\
& n_{\text {actual }}(\operatorname{Rec} 1)=\frac{n_{\text {theo }}(\operatorname{Rec} 1)-1}{0.8}
\end{aligned}
$$

The rectification column is assumed to operate at atmospheric pressure $\left(P_{\text {Rec } 1}=1\right.$ atm). A pressure drop of $0.1 \mathrm{~atm}$ across the rectification column $\left(\Delta P_{R e c 1}\right)$ is assumed. Therefore, the temperature of the inlet stream is calculated at $1 \mathrm{~atm}$, that of the reboiler and the condenser are computed at $1.05 \mathrm{~atm}$ and $0.95 \mathrm{~atm}$, respectively.

The dew point equation (DPE) is again used to relate the temperature inside the condenser with the mass fractions of the components inside the vapor distillate and the refluxed liquid. A reflux ratio $\left(R_{R e c 1}\right)$ of 2 is taken for the rectifier column. Since water and ethanol are the only components in the condenser of the rectifier column, (DPE) reduces to the following:

$$
\begin{aligned}
& m f(j, R e c 1, S p l 4) . \sum_{h=\{\text { ethanol,water }\}} \frac{x(h, R e c 1, S p l 4)}{M W_{h}}=\frac{x(j, R e c 1, S p l 4)}{M W_{j}} \quad j=\{\text { ethanol, water }\} \\
& \exp \left(A_{\text {ethanol }}-\frac{B_{\text {ethanol }}}{T(\text { Recl } 1, S p l 4)+C_{\text {ethanol }}}\right)=\left(P_{\text {Recl }}-\frac{\Delta P_{\text {Recl }}}{2}\right) .\left(m f(\text { water, Rec1,Spl4 }) . \alpha_{\text {ethanollwater }}+m f(\text { ethanol Recl, Spl4 })\right)
\end{aligned}
$$

Vapor-liquid equilibrium in the rectification column condenser is modeled as follows:

$$
\begin{aligned}
& l f_{\text {Rec1 } 1}(\text { ethanol })=\frac{m f(\text { ethanol, Rec1, Spl4 }) \cdot\left(P_{\text {Rec1 } 1}-\frac{\Delta P_{\text {Rec1 }}}{2}\right)}{\exp \left(A_{\text {ethanol }}-\frac{B_{\text {ethanol }}}{T(\text { Rec1, Spl } 4)+C_{\text {ethanol }}}\right)} \\
& l f_{\text {Recl }}(\text { water })=1-l f_{\text {Recl }}(\text { ethanol }) \\
& x f_{\text {Rec1 }}(j) . \sum_{h=\{\text { ethanol,water }\}} l f_{\text {Rec }}(h) \cdot M W_{h}=l f_{\text {Rec1 } 1}(j) \cdot M W_{j} \quad j=\{\text { ethanol, water }\}
\end{aligned}
$$


Finally, the cooling heat load required for the condenser of the rectifier column is given by eq (89).

$$
Q_{-} \operatorname{cond}(\operatorname{Rec} 1)=-F(\operatorname{Rec} 1, \operatorname{Spl} 4) \cdot R_{\text {Rec1 } 1} \cdot \sum_{h=\{\text { ethanol, water }\}} x f_{\text {Rec } 1}(h) \cdot \Delta H_{v}^{0}(h) \cdot\left(\frac{T_{c}(h)-T(\operatorname{Rec} 1, \operatorname{Spl} 4)}{T_{c}(h)-T_{b}(h)}\right)^{n_{\text {watson }}}
$$

$\mathrm{Eq}(\mathrm{BPE})$ is again used to calculate the reboiler temperature for the rectification column.

$$
\begin{aligned}
& m f(j, \operatorname{Rec} 1, \operatorname{Snk} 2) . \sum_{h=\{\text { ethanol,water }\}} \frac{x(h, \operatorname{Rec} 1, \operatorname{Snk} 2)}{M W_{h}}=\frac{x(j, \operatorname{Rec} 1, \operatorname{Snk} 2)}{M W_{j}} \quad j=\{\text { ethanol, water }\} \quad \text { (90) } \\
& P_{\operatorname{Rec} 1}+\frac{\Delta P_{\operatorname{Rec} 1}}{2}=\left(m f(\text { Water }, \operatorname{Re} c 1, \operatorname{Sn} k 2)+\alpha_{\text {ethanol } / \text { water }} . m f(\text { Ethanol, } \operatorname{Re} c 1, \operatorname{Snk} 2)\right) \cdot \exp \left(A_{\text {water }}-\frac{B_{\text {water }}}{T(\operatorname{Re} c 1, \operatorname{Snk} 2)+C_{\text {water }}}\right)
\end{aligned}
$$

The heat balance in the reboiler is given by:

$$
Q_{-} \operatorname{reb}(\operatorname{Rec} 1)=\left(F(\operatorname{Rec} 1, \operatorname{Spl} 4) \cdot R_{\text {Rec1 }}-F(\operatorname{Rec} 1, \operatorname{Snk} 2)\right) \cdot \Delta H_{v}^{0}(\text { Water }) \cdot\left(\frac{T_{c}(\text { Water })-T(\operatorname{Rec} 1, \operatorname{Snk} 2)}{T_{c}(\text { Water })-T_{b}(\text { Water })}\right)^{n_{\text {watson }}}
$$

Finally, the heat from the bottoms stream can also be recovered by placing a heat exchanger after Snk2. The total amount of heat recovered is given by :

$Q_{-} \operatorname{bottom}(\operatorname{Rec} 1)=\sum_{h=\{\text { ethanol, water }\}} f c(h e c 1, \operatorname{Snk} 2) \cdot \operatorname{Cp}(h) \cdot\left(T_{\text {cooldown }}-T(\operatorname{Rec} 1, \operatorname{Snk} 2)\right)$

In the above equation, $T_{\text {cooldown }}$ is set to $25^{\circ} \mathrm{C}$.

The outlet from the rectifier can be sent directly to the ethanol outlet, or to the adsorption bed made of corn grits, or to the molecular sieve (see Fig. 2). This is modeled as follows:

$$
\begin{aligned}
& F(\operatorname{Re} c 1, \operatorname{Spl} l 4)=F(\operatorname{Spl} 4, \operatorname{Mix} 5)+F(\operatorname{Spl4}, \operatorname{Mix} 6)+F(\operatorname{Spl4}, \operatorname{Mix} 7) \\
& x(j, \operatorname{Spl} 4, \text { Mix } 5)=x(j, \text { Rec1, Spl4 }) \quad j=\{\text { ethanol, water }\} \\
& x(j, \text { Spl4,Mix } 6)=x(j, \text { Rec1, Spl4 }) \quad j=\{\text { ethanol, water }\} \\
& x(j, \text { Spl4, Mix } 7)=x(j, \text { Rec1, Spl4 }) \quad j=\{\text { ethanol, water }\} \\
& T(\operatorname{Spl} 4, \operatorname{Mix} 5)=T(\operatorname{Rec} 1, \operatorname{Spl} 4) \\
& T(\operatorname{Spl} 4, \operatorname{Mix} 6)=T(\operatorname{Rec} 1, \operatorname{Spl} 4) \\
& T(\operatorname{Spl} 4, \operatorname{Mix} 7)=T(\operatorname{Rec} 1, \operatorname{Spl} 4)
\end{aligned}
$$


(vii) Adsorption of water on corn grits

The feed for the adsorption unit $(A d s 1)$ can come from the rectification column as well as from the beer column. Some researchers have investigated the use of biomaterials as absorbents (Ladisch et al., 1984; Beery and Ladisch, 2001). The results show great promise for reducing the energy consumption in the ethanol purification part of the plant. A bed made of corn grits (composition shown in Table 4 (Beery and Ladisch, 2001)) selectively adsorbs water from an ethanol-water vapor mixture coming from the mixer Mix5. The corn grits for this bed come from a source unit $(\operatorname{Src} 9)$. Heat exchanger $H X 6$ heats the corn grits to the adsorption temperature ( $\left.T \_a d s\right)$. The bed adsorbs water from the ethanol-water vapor mixture and the ethanol passes on to the splitter Spl5. The ethanol-water mixture rises to the bed temperature as the water adsorbs into the bed. The maximum concentration of ethanol obtainable at the outlet of the bed is assumed to be $97.7 \% \mathrm{w} / \mathrm{w}$ (Ladisch and Dyck, 1979). After the bed is saturated with water, the wet corn grits are sent to a splitter Spl6, and from there they can be sent to both the mixer Mix2, and/ or to sink Snk3, while fresh adsorbent enters the column and a new adsorber bed is formed. An alternative scheme is to use two corn grit beds working in parallel, one being saturated with water while the other is being dehydrated (or regenerated). For the costing analysis of the overall plant, we consider a dual-bed corn grit adsorber, although the energy cost for the regeneration of the bed was is taken into account. Note that the corn grits saturated with water can be used as fermentation substrate, although that possibility is not considered in the model. The schematic of a corn bed adsorber appears in Fig. 10.

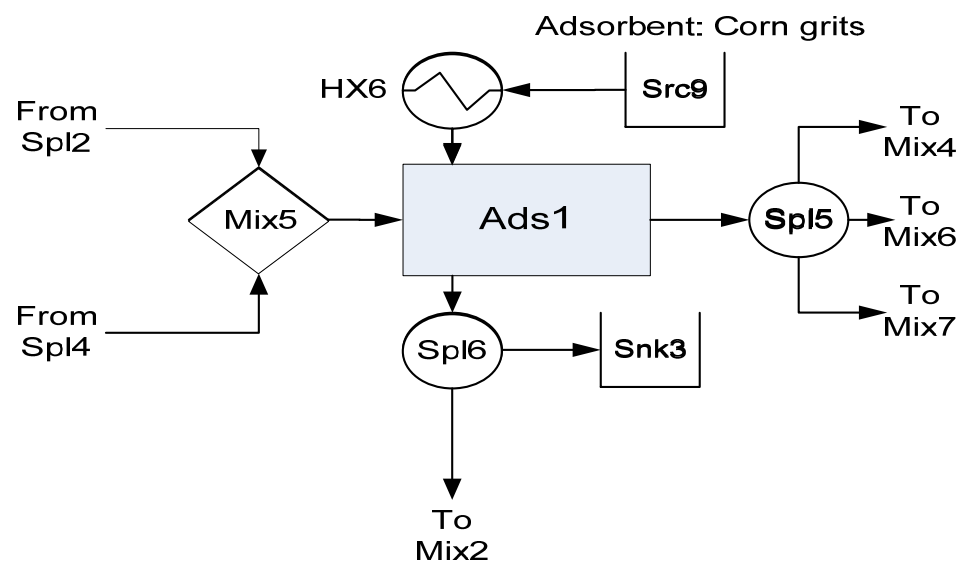

Fig. 10 Corn bed adsorber 
The mixer Mix 5 is modeled as follows:

$$
\begin{aligned}
& f c(j, \text { Mix } 5, A d s 1)=f c(j, \text { Spl2,Mix } 5)+f c(j, \text { Spl4,Mix } 5) \quad j=\{\text { ethanol }, \text { water }\} \\
& \sum_{h=\{\text { ethanol,water }\}}\left(f \mathcal{c}(h, \operatorname{Spl2,Mix} 5) \cdot C p^{v a p}(h)\right) .(T(M i x 5, A d s 1)-T(\operatorname{Spl2,Mix5})) \\
& +\sum_{h=(\text { ethanol,water })}\left(f c(h, \operatorname{Spl} l, M i x 5) \cdot C p^{\text {vap }}(h)\right) \cdot(T(M i x 5, A d s 1)-T(\operatorname{Spl} 4, \text { Mix } 5))=0
\end{aligned}
$$

The flow balances for the corn grit bed are as follows:

$$
\begin{aligned}
& f c(\text { Ethanol, Ads1,Spl5 })=f c(\text { Ethanol, Mix 5, Ads1 }) \\
& f c(j, \operatorname{Src} 9, H X 6)=x_{a d s}(j) \cdot F(\operatorname{Src} 9, H X 6) \quad \forall j \in J, j \neq\{\text { carbon dioxide, oxygen }\} \\
& f c(j, H X 6, A d s 1)=x_{a d s}(j) \cdot F(\operatorname{Src} 9, H X 6) \quad \forall j \in J, j \neq\{\text { carbon dioxide, oxygen }\} \\
& f c(j, A d s 1, \operatorname{Spl6})=x_{a d s}(j) \cdot F(\operatorname{Src} 9, H X 6) \quad \forall j \in J, j \neq\{\text { ethanol,water }\} \\
& f c(\text { water }, A d s 1, S p l 5)=\left(1-\text { rem }_{a d s}\right) \cdot f c(\text { water }, \text { Mix } 5, \text { Ads } 1)
\end{aligned}
$$

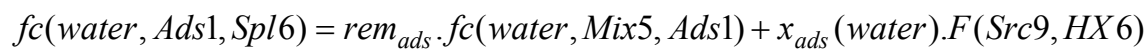

Here, $x_{a d s}(j)$ is the fraction of component $j$ in the corn grit bed (see Table 4), while rem $_{a d s}$ is the fraction of water removed from the incoming ethanol-water vapor mixture. There is a lower limit on the fraction of ethanol that can be present in the vapor stream entering the adsorber denoted by $x_{i n, a d s}^{\text {ethanol,min }}$, and there is an upper bound on the

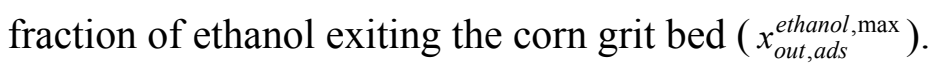

The heat balance in the heat exchanger $H X 6$ is given by,

$Q(H X 6)=\sum_{j} f c(j, H X 6, A d s 1) \cdot C p(j) \cdot(T(H X 6, A d s 1)-T(\operatorname{Src} 9, H X 6))$

\section{Table 4. Composition of corn grit bed}

\begin{tabular}{|l|l|}
\hline Component & Mass fraction \\
\hline Starch & 0.8810 \\
\hline Protein & 0.0847 \\
\hline Oil & 0.0079 \\
\hline Ash & 0.0034 \\
\hline Cellulose & 0.0069 \\
\hline Hemicellulose & 0.0161 \\
\hline
\end{tabular}

Data for adsorption on corn grits is summarized in Table 5 (Beery and Ladisch, 2001; Ladisch and Dyck, 1979). 
Table 5. Data for adsorption on corn grits

\begin{tabular}{|l|l|}
\hline Parameter & Value \\
\hline$x_{\text {in, } \text { edd }}^{\text {ethol,min }}$ & 0.77 \\
\hline$x_{\text {out,ads }}^{\text {ethan }}$ & 0.977 \\
\hline$a_{\text {ads_potential }}{ }_{\text {Ads } 1}(\mathrm{~kg}$ water adsorbed $/ \mathrm{kg}$ adsorbent $)$ & 0.075 \\
\hline
\end{tabular}

The amount of water being adsorbed by the corn grits divided by the adsorption potential gives the required bed size $\left(\right.$ size $\left._{A d s 1}\right)$ on a mass basis and this is modeled with the following two equations,

$$
\begin{aligned}
& F(\operatorname{Src} 9, H X 6)=\left(1 / a_{d}{ }_{2} \text { potential }_{A d s 1}\right) \cdot r e m_{a d s} . f c(\text { water }, \text { Mix } 5, \text { Ads } 1) \\
& \text { size }_{A d s 1}=F(\operatorname{Src} 9, H X 6) . t_{-} a d s_{\text {saturation }}
\end{aligned}
$$

where, ads_potential ${ }_{A d s 1}$ is the mass of water adsorbed per unit mass of corn grit bed and $t_{-} a d s_{\text {saturation }}=3600 \mathrm{~s}$ is an assumption for the time required for the corn grit bed to reach saturation. The splitters Spl5 and Spl6 following the corn grit adsorber are modeled using the following set of equations:

$$
\begin{aligned}
& F(A d s 1, \operatorname{Spl5})=F(\operatorname{Spl5}, \operatorname{Mix} 4)+F(\operatorname{Spl5}, \operatorname{Mix} 6)+F(\operatorname{Spl5}, \operatorname{Mix} 7) \\
& x(j, \text { Spl5,Mix } 4)=x(j, A d s 1, \text { Spl5 }) \quad j=\{\text { ethanol,water }\} \\
& x(j, \text { Spl5,Mix } 6)=x(j, A d s 1, \text { Spl5 }) \quad j=\{\text { ethanol,water }\} \\
& x(j, \operatorname{Spl5}, \text { Mix } 7)=x(j, \text { Ads } 1, \text { Spl5 }) \quad j=\{\text { ethanol, water }\} \\
& T(\operatorname{Spl5}, \operatorname{Mix} 4)=T(A d s 1, S p l 5) \\
& T(\operatorname{Spl5}, \operatorname{Mix} 6)=T(A d s 1, S p l 5) \\
& T(\operatorname{Spl5}, \operatorname{Mix} 7)=T(A d s 1, \operatorname{Spl5}) \\
& F(A d s 1, \operatorname{Spl6})=F(\operatorname{Spl6}, \operatorname{Mix} 2)+F(\operatorname{Spl6}, \operatorname{Snk} 3) \\
& x(j, \text { Spl } 6, \text { Mix } 2)=x(j, \text { Ads } 1, \text { Spl6 }) \quad \forall j \in J, j \neq\{\text { Carbon dioxide, Oxygen }\} \\
& x(j, \text { Spl6,Snk3 })=x(j, \text { Ads } 1, \text { Spl6 }) \quad \forall j \in J, j \neq\{\text { Carbon dioxide, Oxygen }\} \\
& T(\operatorname{Spl6}, \operatorname{Mix} 2)=T(A d s 1, \text { Spl6 }) \\
& T(\operatorname{Spl6}, \operatorname{Snk} 3)=T(A d s 1, \operatorname{Spl6})
\end{aligned}
$$

For the optimization, the flow $F(\operatorname{Spl6,Mix} 2)$ is set to zero, implying no recycle of the corn grits saturated with water.

\section{(viii) Molecular sieves}

Since a purity of $99.9 \% \mathrm{w} / \mathrm{w}$ of ethanol is required for fuel grade ethanol, molecular sieves are always needed if energy consuming azeotropic distillation or the 
use of entrainers in the distillation processes is to be avoided. Distillation at atmospheric pressure can only achieve the azeotropic concentration. A molecular sieve selectively adsorbs water from an ethanol-water mixture and $100 \%$ pure ethanol is obtained at the outlet. The molcular sieve is a bed of zeolite that operates in semi-continuous mode. The bed gets saturated with water after a period of time and is then regenerated. Hence, there are usually two sieves being operated in parallel - one being saturated with water (MS1) while the other (MS2) is being regenerated (or dehydrated). The molecular sieves switch every time the hydrating bed gets saturated with water.

For dehydrating the molecular sieve we employ dry air because it is cheaper than alternatives such as steam. The schematic of the operation of the molecular sieves is shown in Fig. 11.

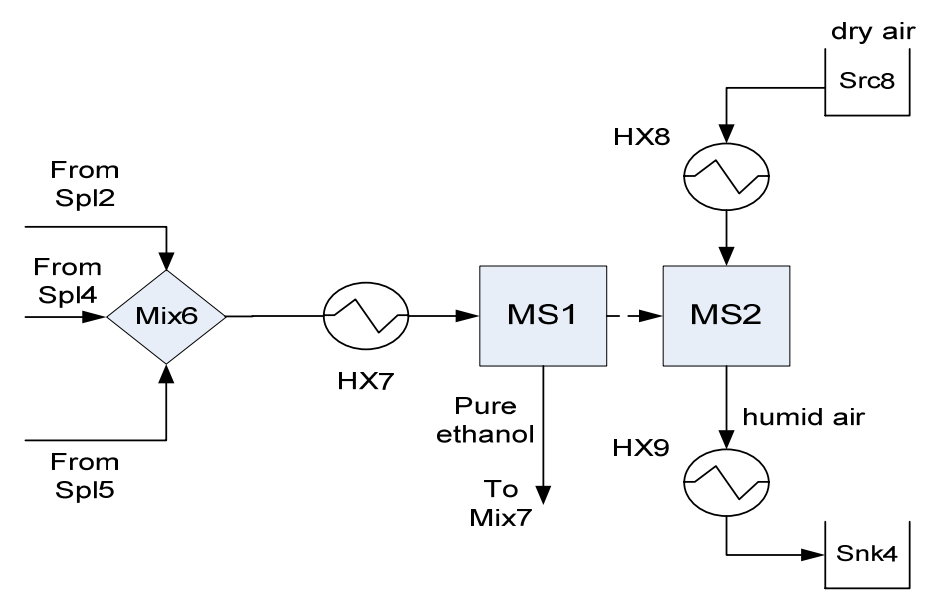

\section{Fig. 11 Molecular sieves operating in parallel}

Adsorption takes place at $95{ }^{\circ} \mathrm{C}$ and at atmospheric pressure. Heat exchanger $H X 7$ brings the inlet stream from the mixer Mix 6 up to $95^{\circ} \mathrm{C}$. The heat of adsorption is assumed to be stored in the bed and provides the heat of desorption while regenerating.

The feed for the molecular sieves can come from the outlet of the corn grit bed adsorber or from the distillation columns, and these streams are mixed in mixer Mix 6 to generate an inlet stream for the molecular sieve MS1. The energy and component mass balances for mixer Mix6 are as follows: $f c(j$, Mix $6, H X 7)=f c(j, S p l 2, \operatorname{Mix} 6)+f c(j, \operatorname{Spl} 4, \operatorname{Mix} 6)+f c(j$, Spl5,Mix 6$) \quad j=\{$ ethanol, water $\}$ 


$$
\begin{aligned}
& \sum_{h=\{\text { ethanol,water }\}}\left(f_{\mathcal{C}}(h, S p l 2, \operatorname{Mix} 6) \cdot C p^{\text {vap }}(h)\right) \cdot(T(\operatorname{Mix} 6, H X 7)-T(\operatorname{Spl} 2, \operatorname{Mix} 6)) \\
& +\sum_{h=(\text { ethanol,water })}\left(f c(h, S p l 4, \operatorname{Mix} 6) \cdot C p^{v a p}(h)\right) \cdot(T(\operatorname{Mix} 6, H X 7)-T(\operatorname{Spl} 4, M i x 6)) \\
& +\sum_{h=(\text { ethanol,water }\}}\left(f c(h, S p l 5, M i x 6) \cdot C p^{v a p}(h)\right) \cdot(T(M i x 6, H X 7)-T(S p l 5, M i x 6))=0
\end{aligned}
$$

The water and ethanol balances for both the beds and the heat exchangers $H X 7$ and $H X 8$ are as follows:

$$
\begin{aligned}
& f_{c}(j, H X 7, M S 1)=f_{c}(j, \text { Mix } 6, H X 7) \quad j=\{\text { ethanol, water }\} \\
& f_{c}(\text { water }, M S 1, M i x 7)=\left(1-\operatorname{rem}_{M S}\right) \cdot f_{c}(\text { water }, H X 7, M S 1) \\
& f_{c}(\text { water }, M S 1, M S 2)=\operatorname{rem}_{M S} \cdot f_{c}(\text { water }, H X 7, M S 1) \\
& f_{c}(\text { ethanol, } M S 1, M i x 7)=f c(\text { ethanol, } H X 7, M S 1) \\
& f c(\text { water }, \operatorname{Src} 8, H X 8)=F^{\text {dryair }} . s h_{i n, M S} \\
& f c(\text { water }, H X 8, M S 2)=F^{\text {dryair }} . s h_{i n, M S} \\
& f_{c}(\text { water }, M S 2, H X 9)=f_{c}(\text { water }, H X 8, M S 2)+f_{c}(\text { water }, M S 1, M S 2) \\
& f c(\text { water }, H X 9, S n k 4)=f c(\text { water }, M S 2, H X 9)
\end{aligned}
$$

Here $\mathrm{rem}_{M S}$ is the fraction of incoming water removed in the hydrating molecular sieve, $F^{\text {dryair }}$ is the flow of dry air used to dehydrate the regenerating molecular sieve $(\mathrm{kg} / \mathrm{s})$, and $s h_{i n, M S}$ is the specific humidity ( $\mathrm{kg}$ water/ $\mathrm{kg}$ dry air) in the inlet air stream to the regenerating molecular sieve. There is a lower bound on the fraction of ethanol entering the molecular sieve $\left(x_{i n, M S}^{\text {ethanol, } \min }=0.8\right)$.

The heat input in the heat exchanger $H X 7$ is given by:

$$
Q(H X 7)=\sum_{h=\{\text { ethanol,water }\}} f c(h, M i x 6, H X 7) \cdot C p^{v a p}(h) .(T(H X 7, M S 1)-T(M i x 6, H X 7))
$$

The size of the equipment is given by the quantity of water to be absorbed.

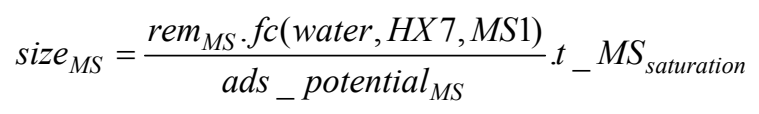

Here ads_potential $M_{M S}$ is the mass of water adsorbed per unit mass of molecular sieve bed, size $_{M S}$ is the mass of molecular sieve beds (in $\mathrm{kg}$ ), $t_{-} M S_{\text {saturation }}$ is the saturation time for a single molecular sieve bed (in s).

Air dehydates the regenerating molecular sieve under vacuum. Heat exchanger $H X 8$ heats air with an assumed relative humidity of $70 \%$ at $20{ }^{\circ} \mathrm{C}$ to $95{ }^{\circ} \mathrm{C}$. The specific humidity of air can be calculated from the vapor pressure of the water in the air. The partial pressure of water is given by the relative humidity multiplied with the saturation 
pressure at the given temperature. The relative humidity $(\theta)$ of an air stream is defined as the partial pressure of water in that air stream ( $\left.p p^{\text {water }}\right)$ divided by the saturation pressure of water at the temperature $T$ of the air stream $\left(p_{\text {water }}^{0}(T)\right)$.

$$
\theta=\frac{p p^{\text {water }}}{p_{\text {water }}^{0}(T)}
$$

The vapor pressure of water is calculated using the Antoine equation:

$$
p_{\text {water }}^{0}(T)=\exp \left(A_{\text {water }}-\frac{B_{\text {water }}}{C_{\text {water }}+T}\right)
$$

The specific humidity $(s h)$ for an air stream is then defined as the mass of water per unit mass of dry air.

$$
\begin{aligned}
& \text { sh }=\frac{\text { mass of condensable vapor }}{\text { mass of noncondensable gas }}=\frac{\text { mass of water }}{\text { mass of dry air }}=\text { specific humidity } \\
& s h=\frac{M W_{\text {water }}}{M W_{\text {air }}} \cdot \frac{p p^{\text {water }}}{p p^{\text {air }}}=0.622 \cdot \frac{p p^{\text {water }}}{P_{\text {tot }}-p p^{\text {water }}}
\end{aligned}
$$

where $M W_{\text {water }}$ and $M W_{\text {air }}$ are the molecular weights of water and air, respectively, $\frac{p p^{\text {water }}}{p p^{\text {air }}}$ is the ratio of the partial pressure of water to the partial pressure of dry air in the given moisture laden air stream, and $P_{t o t}$ is the total pressure of the air stream.

The amount of water, which can be adsorbed by an air stream during the regeneration time, is the product of the flow of the dry air stream and the difference in the specific humidity of the air streams at the inlet and the outlet of the molecular sieve being regenerated. These are represented by the following equations:

$$
\begin{aligned}
& p_{\text {water }, \text { in }, M S}^{0}=\exp \left(A_{\text {water }}-\frac{B_{\text {water }}}{C_{\text {water }}+T(\operatorname{Src} 8, H X 8)}\right) \\
& p_{\text {water }, \text { out }, M S}^{0}=\exp \left(A_{\text {water }}-\frac{B_{\text {water }}}{C_{\text {water }}+T(M S 2, H X 9)}\right) \\
& p_{\text {water }, r t}^{0}=\exp \left(A_{\text {water }}-\frac{B_{\text {water }}}{C_{\text {water }}+T(H X 9, \operatorname{Snk} 4)}\right) \\
& p p_{\text {in }, M S}^{\text {water }}=r h_{\text {in, }, M S} \cdot p_{\text {water }, \text { in, }, M S}^{0} \\
& p p_{\text {out }, M S}^{\text {water }}=r h_{\text {out }, M S} \cdot p_{\text {water }, \text { out }, M S}^{0} \\
& p p_{r t}^{\text {water }}=r h_{r t} \cdot p_{\text {water }, r t}^{0} \\
& s h_{r t}=\frac{(0.622) \cdot p p_{r t}^{\text {water }}}{P_{M S}-p p_{r t}^{\text {water }}}
\end{aligned}
$$




$$
\begin{aligned}
& s h_{i n, M S}=\frac{(0.622) \cdot p p_{\text {in }}^{\text {water }}}{P_{M S}-p p_{i n, M S}^{\text {water }}} \\
& s h_{\text {out }, M S}=\frac{(0.622) \cdot p p_{\text {out }, M S}^{\text {water }}}{P_{M S}-p p_{\text {out }, M S}} \\
& F^{\text {dryair }} .\left(s h_{\text {out }, M S}-s h_{i n, M S}\right)=f c(\text { water }, M S 1, M S 2)
\end{aligned}
$$

In the above equations, $p_{\text {water, }, 0, M S}^{0}$ and $p_{\text {water,out,MS }}^{0}$ are the vapor pressures of water in the cold inlet dry air to $H X 8$ and the outlet air stream from the regenerating molecular sieve, respectively, while $p_{\text {water, } r t}^{0}$ is the vapor pressure of water at ambient temperature $\left(25^{\circ} \mathrm{C}\right) . p p_{i n, M S}^{\text {water }}$ and $p p_{\text {out }, M S}^{\text {water }}$ are the partial pressures of water in the inlet dry air to $H X 8$, and the outlet air stream from the regenerating molecular sieve, respectively. $p p_{r t}^{\text {water }}$ stands for the partial pressure of water in an air stream at ambient temperature $\left(25^{\circ} \mathrm{C}\right)$. The total pressure of the air stream entering the regenerating molecular sieve is given by $P_{M S}$. The terms $r h_{i n, M S}$ and $r h_{\text {out }, M S}$ denote the relative humidity in the inlet air stream before $H X 8$, and the outlet air stream from the regenerating molecular sieve, respectively, while $r h_{r t}$ is the relative humidity in an air stream at room temperature $\left(25^{\circ} \mathrm{C}\right) . s h_{r t}$ is the specific humidity in an air stream at room temperature $\left(25^{\circ} \mathrm{C}\right), s h_{i n, M S}$ is the specific humidity in the inlet air stream to the regenerating molecular sieve, while $s h_{\text {out }, M S}$ is the specific humidity in the outlet air stream from the regenerating molecular sieve. The partial pressures are in $\mathrm{mm} \mathrm{Hg}$ while the relative humidities are in fractions.

The heat input in the heat exchanger $H X 8$ is given by:

$$
Q(H X 8)=F^{\text {dryair }} \cdot\left(C p^{\text {dryair }}+s h_{\text {in, MS }} \cdot C p^{\text {vap }}(\text { water })\right) \cdot(T(H X 8, M S 2)-T(\operatorname{Src} 8, H X 8))
$$

where $C p^{\text {dryair }}$ is the specific heat capacity of dry air (in $\left.\mathrm{kJ} / \mathrm{kg}^{\circ}{ }^{\circ} \mathrm{C}\right)$.

The hot moisture laden air at the outlet of the dehydrating molecular sieve is cooled to $25{ }^{\circ} \mathrm{C}$ in heat exchanger $H X 9$ and this stream leaves this exchanger saturated with water at $25^{\circ} \mathrm{C}$. The heat loss in this case (including condensation of water) is given by:

$$
\begin{aligned}
Q(H X 9)= & F^{\text {dryair }} \cdot\left(C p^{\text {dryair }}+s h_{\text {out }, M S} \cdot C p^{\text {vap }}(\text { water })\right) \cdot(T(H X 9, \text { Snk } 4)-T(M S 2, H X 9)) \\
& +F^{d r y a i r} \cdot\left(s h_{r t}-s h_{\text {out }, M S}\right) \cdot \Delta H_{v}^{0}(\text { water }) \cdot\left(\frac{T_{c}(\text { water })-T(H X 9, \text { Snk } 4)}{T_{c}(\text { water })-T_{b}(\text { water })}\right)^{n_{\text {watson }}}
\end{aligned}
$$

The data used in the model for the molecular sieves is mostly assumed in the ranges taken from Jacques et al. (1999) and is summarized in Table 6. 
Table 6. Data for molecular sieves

\begin{tabular}{|c|c|}
\hline Parameter & Value \\
\hline$x_{\text {in,MS }}^{\text {ethanol,min }}$ & 0.8 \\
\hline $\begin{array}{c}a d s_{-} \text {potential } \\
\text { (kg water } / \mathrm{kg}\end{array}$ & 0.08 \\
\hline $\begin{array}{c}\text { adsorbent) } \\
t_{-} M S_{\text {saturation }}(\mathrm{s})\end{array}$ & 360 \\
\hline$r h_{\text {in,MS }}(\%)$ & 70 \\
\hline$r h_{\text {out }, M S}(\%)$ & 70 \\
\hline
\end{tabular}

(ix) Ethanol recovery

The purified ethanol vapor streams coming from the rectifier, the corn grit adsorber, and the molecular sieves mix in mixer Mix7, condense in condenser Cond1, and then cool to final product temperature. The condensation is assumed to take place at the boiling point of ethanol as the outlet stream is almost pure ethanol. This nearly pure ethanol stream is then cooled to room temperature in heat exchanger $H X 5$ from where it goes to Snk5. The mass and energy balances in this part of the superstructure (see Fig. 2) are as follows:

$$
\begin{aligned}
& f c(j, \operatorname{Mix} 7, \operatorname{Cond} 1)=f c(j, \operatorname{Spl} 4, \operatorname{Mix} 7)+f c(j, \operatorname{Spl5}, \operatorname{Mix} 7)+f c(j, M S 1, \text { Mix } 7) \quad j=\{\text { ethanol, water }\} \\
& \sum_{h=\{\text { ethanol,water }\}}\left(f c(h, \operatorname{Spl} 4, \operatorname{Mix} 7) \cdot C p^{\text {vap }}(h)\right) .(T(\operatorname{Mix} 7, \operatorname{Cond} 1)-T(\operatorname{Spl} 4, \operatorname{Mix} 7)) \\
& +\sum_{h=(\text { ethanol,water }\}}\left(f c(h, \operatorname{Spl5}, \operatorname{Mix} 7) \cdot C p^{v a p}(j)\right) \cdot(T(M i x 7, \text { Cond } 1)-T(\operatorname{Spl5}, \text { Mix7 })) \\
& +\sum_{h=\{\text { ethanol,water }\}}(f c(h, M S 1, M i x 7) \cdot C p(j)) \cdot(T(M i x 7, \operatorname{Cond} 1)-T(M S 1, M i x 7))=0 \\
& f c(j, \text { Cond } 1, H X 5)=f c(j, \text { Mix } 7, \text { Cond } 1) \quad j=\{\text { ethanol, water }\} \\
& Q(\text { Cond } 1)=\sum_{h=\{\text { ethanol,water }\}} f c(h, \text { Mix } 7, \text { Cond } 1) \cdot \Delta H_{v}^{0}(h) \cdot\left(\frac{T_{c}(h)-T(\text { Mix } 7, \text { Cond } 1)}{T_{c}(h)-T_{b}(h)}\right)^{n_{\text {watson }}} \\
& f_{\mathcal{C}}(j, H X 5, \operatorname{Snk} 5)=f_{\mathcal{C}}(j, \text { Cond } 1, H X 5) \quad j=\{\text { ethanol, water }\} \\
& Q(H X 5)=\sum_{h=\{e t h a n o l, \text { water }\}} f c(h, C o n d 1, H X 5) . C p(h) .(T(H X 5, \text { Snk5 })-T(\text { Cond } 1, H X 5))
\end{aligned}
$$

\section{Solids recovery from fermentor as by-product}

Residual fermentation solids are recovered and processed for use in cattle feed. A mechanical press can be used for separating the solids from the liquid either before 
the beer column or after the beer column. We define two binary parameters that are set to values of 0 or 1 , depending on the placement of the mechanical press and other process units for solids processing. The binary parameter $z_{M e c P-B C}$ is set equal to 1 if solids separation takes place before the beer column, otherwise it is set to a value of 0 . The section of the flowsheet corresponding to the solids separation before the beer column is shown in Fig. 12a. The case when the solids separation takes place after the beer column is depicted in Fig. 12b. If this is the case, the binary parameter $z_{B C-M e c P}$ is set equal to a value of 1 . Note that exactly one of the binary parameters $z_{M e c P-B C}$ and $z_{B C-M e c P}$, is set to a value of 1 , while the other is set to 0 .

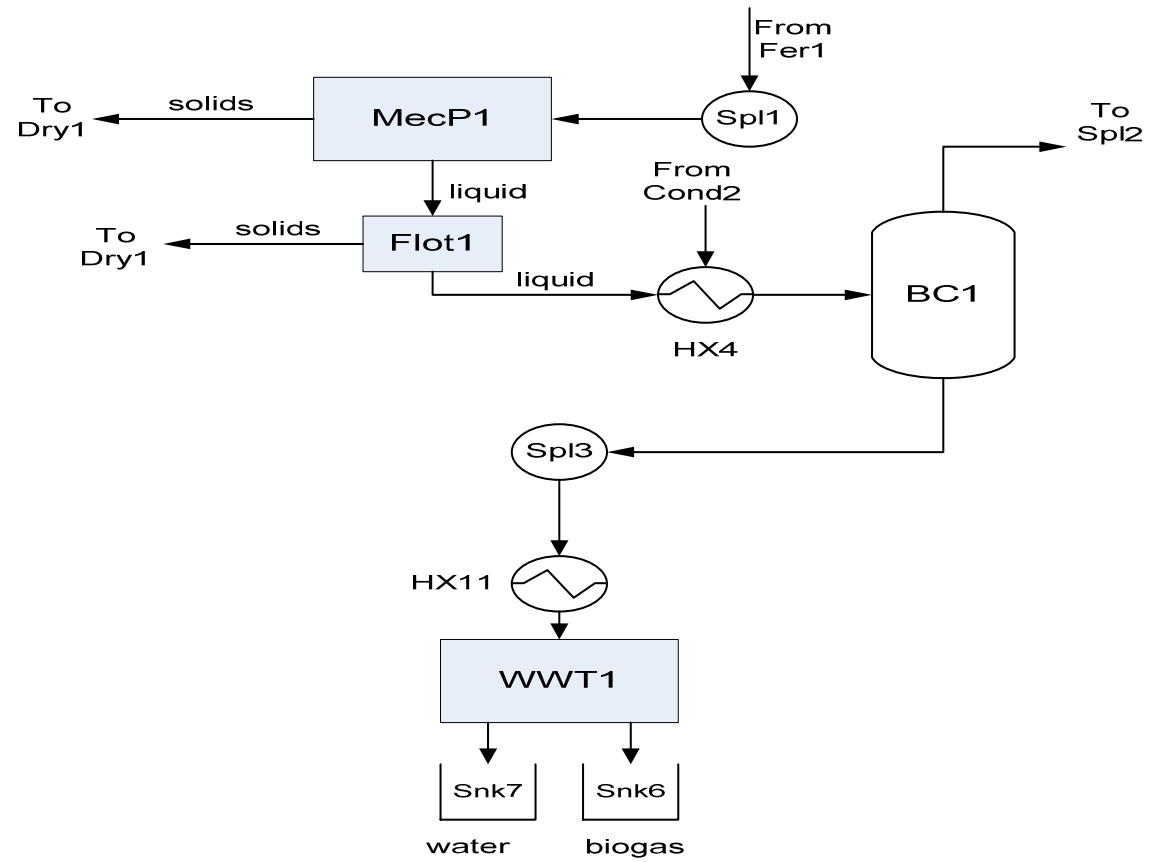

Fig. 12a Case when solids separation takes place before beer column 


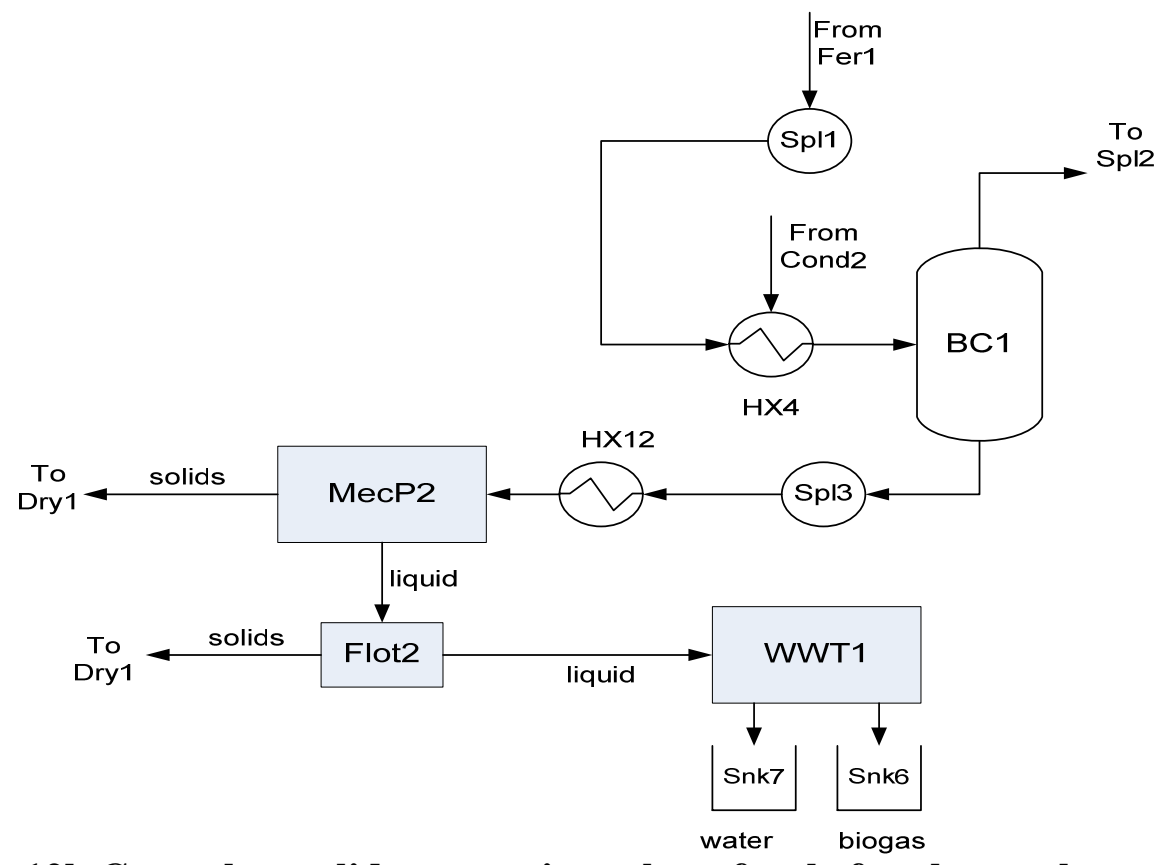

Fig. 12b Case when solids separation takes after before beer column

In the solid-liquid separation section we initially use a mechanical press and a protein recovery flotation unit. The components carbon dioxide and oxygen are not considered in the analysis for this section of the superstructure since they are assumed to have been vented out from the fermentor.

\section{(x) Mechanical press}

There are two mechanical presses shown in the superstructure (Fig. 2), MecPl (placed before the beer column) and $\mathrm{MecP} 2$ (placed after the beer column). Only one of them exists in the actual flowsheet. In order to model the mechanical press, we assume a split fraction for water $\left(\operatorname{split}_{M e c P 1}\right.$ for $M e c P 1$, and $\operatorname{split}_{M e c P 2}$ for $\left.M e c P 2\right)$ in the incoming feed that also decides how much of each component goes with the liquid and how much stays with the solids at the outlet of the mechanical press. The split fractions of the liquids and the solubles are coupled to the split fraction of water. It is assumed that ethanol, glucose, maltose, urea, glycerol, the acids and protein are completely soluble in water. Starch, cellulose, hemicellulose, ash, oil, and cell mass are taken to be insoluble in water. For the oils, it is assumed that $60 \%$ of the oils stay with the solids and $40 \%$ are in the liquid phase. The solubility factors of all the relevant components in water $\operatorname{sol}(j)$ are summarized in Table 7. 
Table 7. Solubility factors for all components except carbon dioxide and oxygen

\begin{tabular}{|c|c|}
\hline Component & sol(j) \\
\hline Starch & 0 \\
\hline Glucose & 1 \\
\hline Maltose & 1 \\
\hline Protein & 1 \\
\hline Ethanol & 1 \\
\hline Glycerol & 1 \\
\hline Succinic acid & 1 \\
\hline Acetic acid & 1 \\
\hline Lactic acid & 1 \\
\hline Urea & 1 \\
\hline Cell mass & 0 \\
\hline Cellulose & 0 \\
\hline Hemicellulose & 0 \\
\hline Oil & 0.4 \\
\hline Ash & 0 \\
\hline
\end{tabular}

The percentage of liquid in the wet solids cake ( moisture $_{\text {cake }}$ ) coming from the mechanical press is assumed to be at least $40 \%$. The flow balances for the mechanical press are as follows:

$$
\begin{gathered}
x\left(\text { ethanol, MecP } 1, \text { Dry1). } z_{M e c P-B C}+x(\text { water, MecP } 1, \text { Dry } 1) . z_{M e c P-B C}\right. \\
+x(\text { oil }, M e c P 1, D r y 1) . z_{\text {MecP-BC }} \geq \text { moisture }_{\text {cake }} . z_{\text {MecP-BC }}
\end{gathered}
$$

$f c(j$, MecP $1, F l o t 1)=\operatorname{split}_{M e c P 1} \cdot \operatorname{sol}(j) . f c(j, S p l 1$, MecPl $) \quad \forall j \in J, j \neq\{$ carbon dioxide, oxygen $\}$

$f c(j$, MecP1,Dryl $)=\left(1-\right.$ split $\left._{\text {MecP } 1} \cdot \operatorname{sol}(j)\right) \cdot f c(j, S p l 1, M e c P 1) \quad \forall j \in J, j \neq\{$ carbondioxide, oxygen $\}$

$x\left(\right.$ ethanol, MecP2, Dry1). $z_{B C-M e c P}+x\left(\right.$ water,$M e c P 2$, Dry1). $z_{B C-M e c P}$

$$
+x\left(\text { oil }, \text { MecP2,Dry1). } z_{B C-M e c P} \geq \text { moisture }_{\text {cake }} . z_{B C-M e c P}\right.
$$

$f c(j, M e c P 2, F l o t 2)=\operatorname{split}_{M e c P 2} \cdot \operatorname{sol}(j) . f c(j, S p l 3, M e c P 2) \quad \forall j \in J, j \neq\{$ carbondioxide, oxygen $\}$

$f c(j, M e c P 2, D r y 1)=\left(1-\right.$ split $\left._{\text {MecP } 2} \cdot \operatorname{sol}(j)\right) \cdot f c(j, S p l 3$, MecP2 $) \quad \forall j \in J, j \neq\{$ carbondioxide,oxygen $\}$

(xi) Flotation for protein recovery

The liquid outlet from the mechanical press is sent to a flotation unit to recover the proteins, which increase the cattle feed value on being mixed with it. One of the flotation units, Flot1 or Flot2, is chosen for the protein recovery depending on the placement of the mechanical press in the flowsheet. A fractional recovery of 0.95 
(rec_prot) is assumed for the proteins in the flotation process. The proteins recovered from the flotation unit go to the dryer for further processing, while the liquid stream from this process goes to either the beer column or a wastewater treatment unit. It is assumed that a certain amount of water stays with the recovered protein on a unit mass basis (water_prot $=0.1 \mathrm{~kg} / \mathrm{kg}$ of protein recovered). The following equations are used to model the flotation process:

$$
\begin{aligned}
& f c(\text { protein }, \text { Flot } 1, \text { Dry1 })=\text { rec_prot. } f c(\text { protein, MecP1,Flot } 1) . z_{\text {MecP-BC }} \\
& f c(\text { water }, \text { Flot } 1, \text { Dry } 1)=\text { water_prot.rec_prot.fc }(\text { protein, MecP1,Flot } 1) . z_{\text {MecP-BC }} \\
& f c(j, \text { Flot } 1, \text { Dry } 1)+f c(j, \text { Flot } 1, H X 4)=f c(j, \text { MecPl }, \text { Flot } 1) \quad \forall j \in J, j \neq\{\text { carbon dioxide, oxygen }\} \\
& f c(\text { protein, Flot } 2, \text { Dry1 })=\text { rec_prot.fc(protein, MecP2, Flot } 2) . z_{B C-M e c P} \\
& f c(\text { water }, \text { Flot 2, Dry1 })=\text { water_prot.rec_prot. } f(\text { protein, MecP2, Flot } 2) \cdot z_{B C-M e c P} \\
& f c(j, \text { Flot } 2, \text { Dry } 1)+f c(j, F l o t 2, W W T 1)=f c(j, \text { MecP2,Flot } 2) \quad \forall j \in J, j \neq\{\text { carbondioxide, oxygen }\}
\end{aligned}
$$

\section{(xii) Drying of solids}

A dryer (Dryl) reduces the moisture level in the solids coming from the mechanical press and the flotation unit to less than $10 \% \mathrm{w} / \mathrm{w}$ for long term storage. These dried solids are known as Distillers Dried Grains with Solubles (DDGS). The model assumes a steam bundle dryer with a drying efficiency $\left(\eta_{\text {dryer }}\right)$ of 0.85 . The vapor from the dryer is assumed to consist of only ethanol and water and is sent to splitter $S p l 7$, while the solids from the dryer continue on to heat exchanger $H X 10$ for cooling to storage temperature. The schematic of the dryer is shown in Fig. 13.

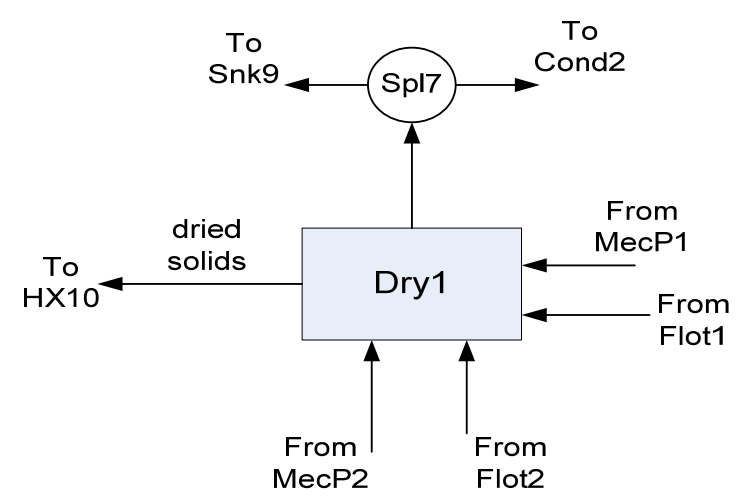

\section{Fig. 13 Schematic of dryer for drying solids}

In the dryer model, the recovery of water $\left(\xi_{\text {water }}\right)$ is defined as the fraction of water in the feed solids that goes to the vapor stream. The recovery of ethanol $\left(\xi_{\text {ethanol }}\right)$ 
is related to the recovery of water by a simple flash calculation (see Biegler et al., 1999).

$$
\xi_{\text {ethanol }}=\frac{\alpha_{\text {ethanol } / \text { water }} \cdot \xi_{\text {water }}}{1+\left(\alpha_{\text {ethanol } / \text { water }}-1\right) \cdot \xi_{\text {water }}}
$$

The mass balances inside the dryer are as follows:

$$
\begin{aligned}
& f c(j, D r y, H X 10)=f c(j, M e c R, D r y 1) \cdot z_{M e c P B C}+f c(j, M e c P 2, D r y) \cdot z_{B C-M e c P} \\
& +f c(j, \text { Flot }, \text { Dryl }) z_{\text {MecP-BC }}+f c(j, \text { Flot } 2, \text { Dryl }) z_{B C-M e c P} \quad \forall j \in J, j \neq\{\text { water,ethanolcarbondioxideoxygen }\}
\end{aligned}
$$

$$
\begin{aligned}
& f c(\text { water }, \text { Dry } 1, S p l 7)=\xi_{\text {water }} \cdot\left(f_{c}(\text { water }, M e c P 1, \text { Dry1 }) \cdot z_{\text {Mec } P-B C}+f_{c}(\text { water }, M e c P 2, \text { Dry } 1) \cdot z_{B C-M e c P}\right. \\
& \left.+f_{c}(\text { water, Flot } 1, \text { Dry } 1) . z_{M e c P-B C}+f c(\text { water, Flot } 2, \text { Dry } 1) . z_{B C-M e c P}\right)
\end{aligned}
$$

$f_{c}($ ethanol, Dry $1, S p l 7)=\xi_{\text {ethanol }} \cdot\left(f_{c}(\right.$ ethanol $, M e c P 1, D r y 1) . z_{M e c P-B C}+f_{c}($ ethanol $, M e c P 2, D r y 1) . z_{B C-M e c P}$ $+f c($ ethanol, Flot 1, Dry 1$) \cdot z_{M e c P-B C}+f c\left(\right.$ ethanol, Flot 2, Dry1). $\left.z_{B C-M e c P}\right)$

$f_{c}($ water, Dry $1, H X 10)=\left(1-\xi_{\text {water }}\right) \cdot\left(f c(\right.$ water $, M e c P 1, D r y 1) . z_{M e c P-B C}+f c($ water $, M e c P 2, D r y 1) \cdot z_{B C-M e c P}$ $+f c($ water, Flot 1, Dry 1$) \cdot z_{M e c P-B C}+f c($ water, Flot 2, Dry 1$\left.) . z_{B C-M e c P}\right)$

$f_{c}\left(\right.$ ethanol, Dry1, HX10) $=\left(1-\xi_{\text {ethanol }}\right) \cdot\left(f c\left(\right.\right.$ ethanol, MecP1,Dry1). $z_{M e c P-B C}+f_{c}($ ethanol, MecP 2, Dry1 $) . z_{B C-M e c P}$ $+f c\left(\right.$ ethanol, Flot 1, Dry1). $z_{M e c P-B C}+f\left(\right.$ ethanol, Flot 2, Dry1). $\left.z_{B C-M e c P}\right)$

The heat balance considers the evaporation enthalpies of water and ethanol as well as the sensible heat required to bring the inlet streams to the drying temperature of $100{ }^{\circ} \mathrm{C}$. The following heat balance yields the dryer heat duty:

$$
\begin{aligned}
& Q(\text { Dry } 1) \cdot \eta_{\text {dryer }}=\sum_{h=\{\text { ethanol, water }\}} f_{c}(h, \operatorname{Dry} 1, \operatorname{Spl} 7) \cdot \Delta H_{v}^{0}(h) \cdot\left(\frac{T_{c}(h)-T(\operatorname{Dry} 1, \operatorname{Spl} 7)}{T_{c}(h)-T_{b}(h)}\right)^{n_{\text {watson }}} \\
& +\sum_{\substack{j \\
j \neq\{\text { carbon dioxide, oxygen }\}}} f c(j, M e c P 1, D r y 1) . z_{M e c P-B C} \cdot C p(j) .(T(\text { Dry } 1, H X 10)-T(M e c P 1, \text { Dry } 1)) \\
& +\sum_{\substack{j \\
j \neq\{\text { carbon dioxide, oxygen }\}}} f_{c}(j, M e c P 2, \text { Dryl }) \cdot z_{B C-M e c P} \cdot C p(j) \cdot(T(\operatorname{Dry} 1, H X 10)-T(M e c P 2, \text { Dry } 1)) \\
& +\sum_{\substack{j \\
j \neq\{\text { carbon dioxide, oxygen }\}}} f_{c}(j, \text { Flot } 1, \text { Dry } 1) . z_{M e c P-B C} \cdot C p(j) .(T(\text { Dry } 1, H X 10)-T(\text { Flot } 1, \text { Dry } 1)) \\
& +\sum_{\substack{j \\
j \neq\{\text { carbon dioxide, oxygen }\}}} f c(j, \text { Flot } 2, \text { Dry } 1) \cdot z_{B C-M e c P} \cdot C p(j) \cdot(T(\text { Dryl } 1, H X 10)-T(F l o t 2, \text { Dry } 1))
\end{aligned}
$$

The vapor coming from the dryer is split in the splitter Spl7 and is sent to a sink Snk9 and to a condenser Cond2. The vapor going into sink $\operatorname{Snk} 9$ is sent to a thermal oxidizer for VOC (volatile organic compounds) removal. We specify bounds on the level of ethanol that can be present in the stream going into Snk9. The following equations describe splitter $S p l 7$, 


$$
\begin{aligned}
& F(\text { Dry } 1, \text { Spl } 7)=F(\text { Spl7, Cond } 2)+F(\text { Spl7, Snk } 9) \\
& x(j, \text { Spl7,Cond } 2)=x(j, \text { Dry } 1, \text { Spl7 }) \quad j=\{\text { ethanol }, \text { water }\} \\
& x(j, \text { Spl } 7, \text { Snk } 9)=x(j, \text { Dry } 1, \text { Spl } 7) \quad j=\{\text { ethanol }, \text { water }\} \\
& T(\text { Spl7, Cond } 2)=T(\text { Dry } 1, \text { Spl } 7) \\
& T(\text { Spl } 7, \text { Snk } 9)=T(\text { Dry } 1, \text { Spl7 })
\end{aligned}
$$

(xiii) Wastewater treatment

The wastewater stream coming from the bottom of the beer column contains many solubles and must be treated in a wastewater treatment unit (WWT1) before it can be discharged into the environment. The organic solubles are anaerobically digested and biogas can be obtained from this process. However, the production of biogas is not considered in the model. In the wastewater treatment process (see Fig. 14), the feed to the unit comes either from heat exchanger $(H X 11)$ or from the flotation unit (Flot2). The treatment unit produces treated water that goes into sink $S n k 7$ and the removed organic components that are collected in Snk6.

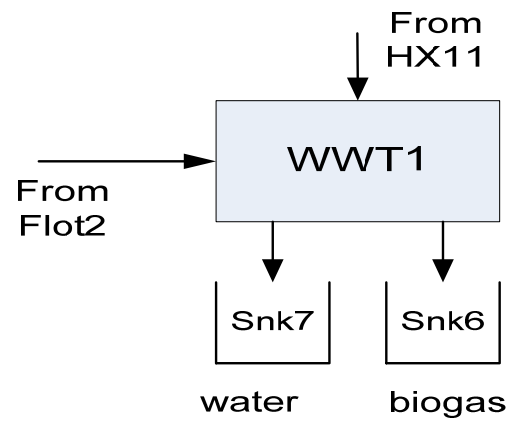

\section{Fig. 14 Wastewater treatment}

The treatment unit is modeled very simply using component removal fractions $\left(\operatorname{rem}_{W W T 1}(j) \quad \forall j\right)$. The removal fraction for all the components except water is assumed to be 0.95 . The parameter $\operatorname{rem}_{W W T 1}$ (water) is assigned a numerical value of 0 .

The component mass balances depend on the removal fractions as shown below:

$$
\begin{array}{r}
f c(j, W W T 1, \operatorname{Snk} 7)=\left(1-\operatorname{rem}_{W W T 1}(j)\right) \cdot\left(f c(j, H X 11, W W T 1) \cdot y_{M e c P-B C}+f c(j, F l o t 2, W W T 1) \cdot y_{B C-M e c P}\right) \\
\forall j \in J, j \neq\{\text { carbon dioxide, oxygen }\} \\
f c(j, W W T 1, \operatorname{Snk} 6)=\operatorname{rem}_{W W T 1}(j) \cdot\left(f \mathcal{C}(j, H X 11, W W T 1) \cdot y_{M e c P-B C}+f c(j, F l o t 2, W W T 1) \cdot y_{B C-M e c P}\right) \\
\forall j \in J, j \neq\{\text { carbon dioxide, oxygen }\}
\end{array}
$$


(xiv) Condenser for dryer vapors

The vapor coming from the dryer is assumed to be only ethanol and water. This stream is split in the splitter $\mathrm{Spl7}$ and a part of it is sent to a total condenser Cond2 which condenses the incoming vapor feed into a saturated liquid. The liquid then passes through heat exchanger $H X 4$. The pressure inside the condenser $\left(P_{\text {Cond } 2}\right)$ is taken to be $760 \mathrm{~mm} \mathrm{Hg}$ (or $1 \mathrm{~atm})$. The following equations describe condenser Cond2:

$f c(j$, Cond $2, H X 4)=f c(j, S p l 7$, Cond 2$) \quad j=\{$ ethanol, water $\}$

$m f\left(j\right.$, Cond 2, HX 4). $\sum_{h=\{\text { ethanol,water }\}} \frac{x(h, \text { Cond } 2, H X 4)}{M W_{h}}=\frac{x(j, \text { Cond } 2, H X 4)}{M W_{j}} \quad j=\{$ ethanol, water $\}$

$P_{\text {Cond } 2}=\left(m f(\right.$ water, Cond $2, H X 4)+\alpha_{\text {ethanol } / \text { water }} \cdot m f($ ethanol, Cond $\left.2, H X 4)\right) \cdot \exp \left(A_{\text {water }}-\frac{B_{\text {water }}}{T(\text { Cond } 2, H X 4)+C_{\text {water }}}\right)$

$Q($ Cond 2$)=-\sum_{h=\{\text { ethanol, water }\}} f c(h$, Cond $2, H X 4) \cdot\left[\operatorname{Cp}^{v a p}(h) \cdot(T(\operatorname{Spl} 7\right.$, Cond 2$\left.)-T(\operatorname{Cond} 2, H X 4))+\Delta H_{v}^{0}(h) \cdot\left(\frac{T_{c}(h)-T(\operatorname{Cond} 2, H X 4)}{T_{c}(h)-T_{b}(h)}\right)^{n_{\text {watson }}}\right]$

In these equations, $m f(j$, Cond $2, H X 4)$ denotes the mole fraction of component $j$ in the liquid stream leaving the condenser Cond2, which is the same as the mole fraction of the component in the vapor inside the condenser.

(xv) Heat exchangers in solids processing section

There are three heat exchangers present in the solids processing section. Heat exchangers $H X 11$ and $H X 12$ cool down the bottoms product from the beer column. Only one of them can exist in a given flowsheet. Heat exchanger $H X 10$ cools the dried solids coming out of the dryer to storage temperature. The following equations describe the heat exchangers in this sub-section of the superstructure (see Fig. 2).

$$
\begin{aligned}
& f_{c}(j, H X 10, \operatorname{Snk} 8)=f c(j, \text { Dry } 1, H X 10) \quad \forall j \in J, j \neq\{\text { carbon dioxide, oxygen }\} \\
& Q(H X 10)=\sum_{\substack{j \\
j \neq\{\text { carbon dioxide, oxygen }\}}} f c(j, \text { Dry } 1, H X 10) \cdot C p(j) \cdot(T(H X 10, \operatorname{Snk} 8)-T(\operatorname{Dry} 1, H X 10)) \\
& f_{c}(j, H X 12, M e c P 2)=f_{c}(j, S p l 3, H X 12) \quad \forall j \in J, j \neq\{\text { carbon dioxide, oxygen }\} \\
& Q(H X 12)=\sum_{\substack{j \\
j \neq\{\text { carbon dioxide, oxygen }\}}} f c(j, \operatorname{Spl}, \operatorname{MecP} 2) \cdot C p(j) \cdot(T(H X 12, M e c P 2)-T(\operatorname{Spl3}, H X 12)) \\
& f c(j, H X 11, W W T 1)=f c(j, S p l 3, H X 11) \quad \forall j \in J, j \neq\{\text { carbon dioxide, oxygen }\}
\end{aligned}
$$


$Q(H X 11)=\sum_{\substack{j \\ j \neq\{\text { carbon dioxide,oxygen }\}}} f c(j, S p l 3, H X 11) \cdot C p(j) \cdot(T(H X 11, W W T 1)-T(\operatorname{Spl3}, H X 11))$

\section{Objective function}

Once all the constraints have been formulated and the variables bounds are set, we seek a design that minimizes the sum of the positive energy input in the network:

$$
\begin{gathered}
\min f=Q(H X 1)+Q(H X 3)+Q(H X 4)+Q(H X 6)+Q(H X 7)+Q(H X 8)+ \\
Q(\text { Jet } 1)+Q(D r y 1)+Q \_r e b(B C 1)+Q \_r e b(\operatorname{Re} c 1)
\end{gathered}
$$

This objective is chosen since most of the utility cost in the plant is due to steam consumption which is used in order to provide heat to some of the units in the plant. We obtain two nonlinear programming models (P1) and (P2) that correspond to the mechanical press placement options. Model (P1) comprises constraints (1)-(178), where

the binary parameter $z_{M e c P-B C}$ is set to 1 and $z_{B C-M e c P}$ is set to 0 . Model (P2) includes equations (1)-(178), where the binary parameter $z_{B C-M e c P}$ is set to 1 and $z_{M e c P-B C}$ is set to 0 . We solve models (P1) and (P2) using GAMS/CONOPT 3.0 and choose the design with the lower objective value. The solution of this optimization is used for further reducing the energy input into the plant using energy reduction techniques as described in the following section.

\section{Alternatives for Energy Reduction}

\subsection{Heat Integration}

Heat integration among the hot and cold streams across the whole plant allows considerable savings in the utilities (steam, cooling water) and consequently in the operating costs (Linnhoff et al., 1982; Biegler et al., 1999). To carry out the heat integration, the software SYNHEAT (http://newton.cheme.cmu.edu/interfaces) was used. This software is based on the work by Yee and Grossmann (1990), and uses an MINLP model that determines a minimum cost network, where the heat exchanger areas and the stream matches are optimized simultaneously, given the heat loads in different streams and the inlet and outlet temperatures of these streams.

\subsection{Multieffect Distillation Columns}

Distillation columns are some of the most energy intensive equipment in the chemical industry. Multieffect distillation column systems can reduce significantly 
steam and cooling water consumption (see Katzen et al., 1980; Biegler et al., 1999). In these systems, a distillation column is replaced by two or more columns. By operating the columns at different pressures the condenser of a higher pressure column serves as the reboiler of the lower pressure column. The inlet feed is split between all the columns, and their top and bottoms products are mixed together to obtain the final products with the desired flowrates and compositions. A schematic of a double effect distillation column is shown in Fig. 15.

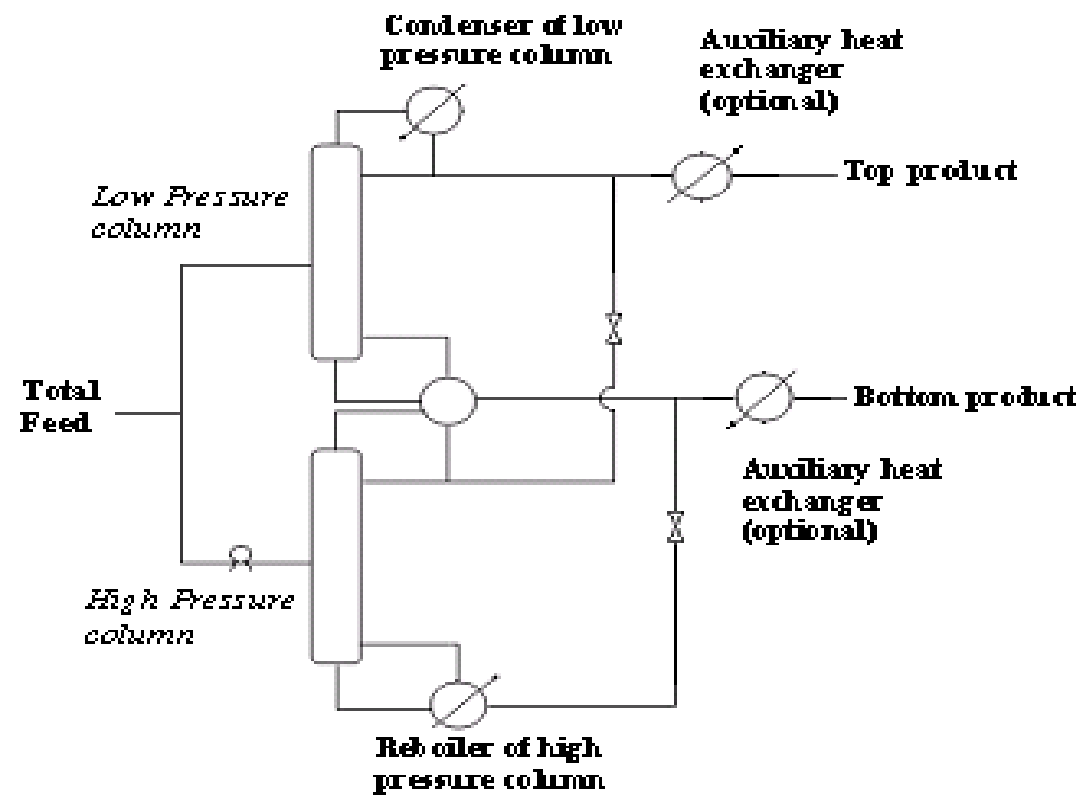

Fig. 15 Multieffect distillation column with two columns

In this work we considered multieffect columns with only two or three columns. For determining the fraction of feed to be sent to each column and the operating pressures of the columns, we set up an optimization model using Microsoft ${ }^{\circledR}$ Excel. The objective of the optimization is to minimize the total annualized cost for the multieffect columns

cost $=$ annualized equipment cost + annual steam cost + annual cooling water cost

subject to the restriction that product composition at the top and bottom of each column must match that obtained for a single distillation column from the results of the previous optimization. This is due to the fact that the superstructure has already optimized the heat loads and this new configuration tries to improve the results. Hence, additional heat exchangers as well as compressors may be required to meet the initial conditions, whose investment cost and utility cost would be included in the total cost objective. Also, 
isenthalpic expansion valves may be needed for some streams so as to match the pressure of the low pressure columns.

\section{Results}

The proposed energy optimization model does not consider feedstock planting, harvesting, handling, or any sort of transportation costs or energy requirements for these pre-processes. The cost of all these pre-processes is assumed to be built into the price of corn that is used as feed. The numerical data used in the optimization and the cost analysis can be obtained from the authors.

We use as case study a plant producing 61.29 M gallons of ethanol a year, operating 360 days per year. The corn feed rate is taken to be $18 \mathrm{~kg} / \mathrm{s}$. The ethanol produced is $2.78 \mathrm{gal} / \mathrm{bu}$ of corn $(1 \mathrm{bu}=56 \mathrm{lb})$. On optimizing the energy input into the plant without any heat integration or structural changes to the distillation columns, a solution of $79,003 \mathrm{~kW}$ (or $38,038 \mathrm{BTU} / \mathrm{gal}$ of ethanol produced) is obtained as the energy required to be input into the plant using steam as the utility. This design corresponds to the case when the mechanical press is placed before the beer column and is shown in Fig. 16. Also, note that the corn grit adsorber bed is used together with the molecular sieves. The total annual production cost for this design is found to be $\$ 1.34$ /gal ethanol and includes the costs for the process equipment, steam and cooling water costs and other miscellaneous costs. The miscellaneous costs include corn cost, electricity cost, general and administrative expenses, employee salaries, cost of chemicals, and maintenance costs. Cost estimation for most of the equipment was done using data from http://www.matche.com/EquipCost/index.htm (as of 10/26/2006) with some adjustments. 


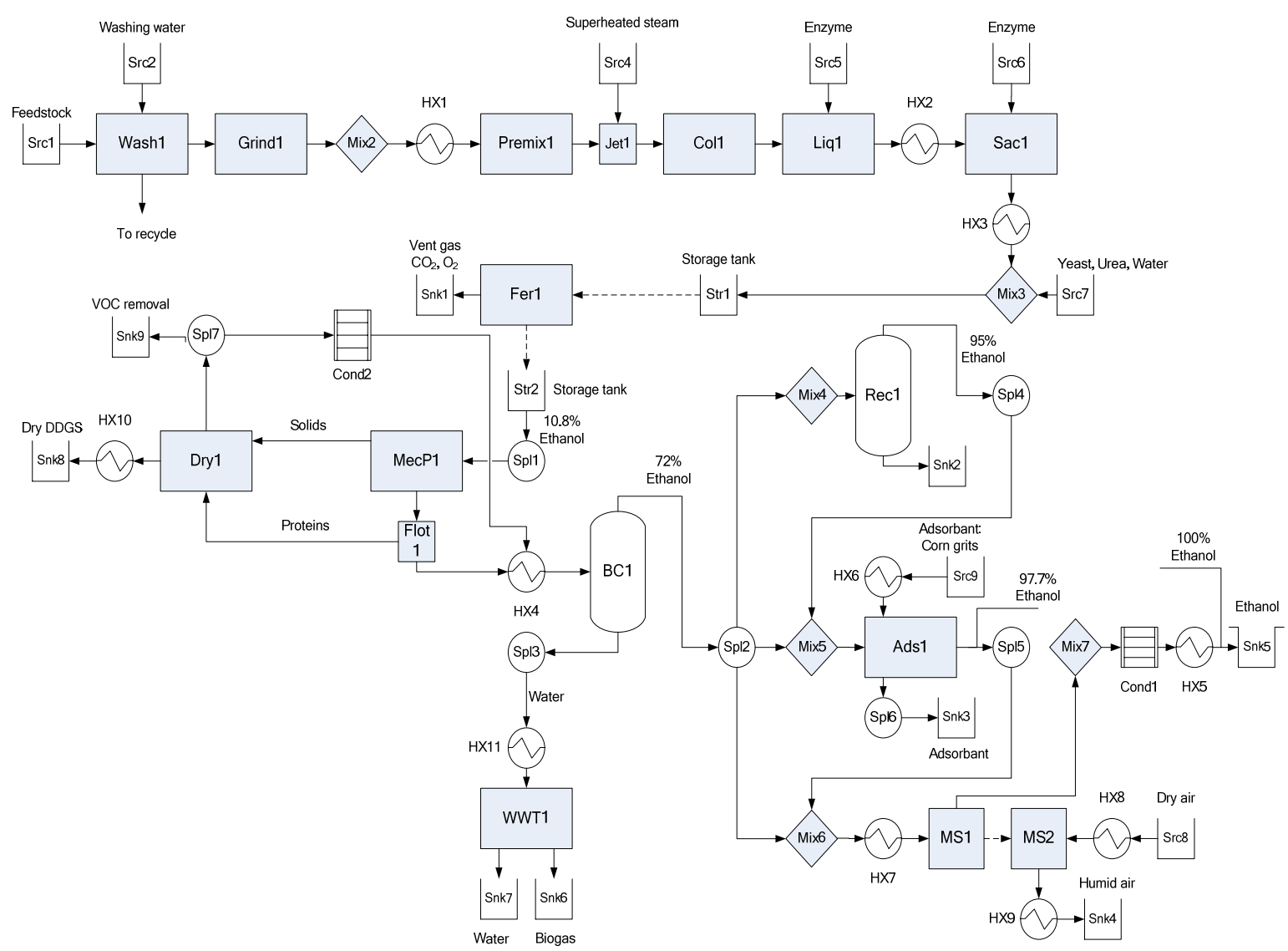

Fig. 16 Optimal design of bioethanol plant producing 61.29 $\mathrm{M}$ gal per year

Using the flowrates, temperatures and compositions of the streams pertaining to various process units in the design, we perform heat integration and are able to reduce the total (steam) energy consumption in the plant to $64,957 \mathrm{~kW}$ (equivalently 31,276 BTU/gal of ethanol produced). On replacing the distillations columns with multieffect columns ( 3 columns for the beer column; 2 columns for the rectification column), and performing an overall heat integration for the plant, we obtain a design that requires only 45,519 kW (or 21,916 BTU/gal ethanol). The multieffect column structures for the beer column and the rectification column appear in Fig. 17a and Fig. 17b, respectively. In these figures, the terms LP, IP, and HP stand for Low Pressure, Intermediate Pressure, and High Pressure. 


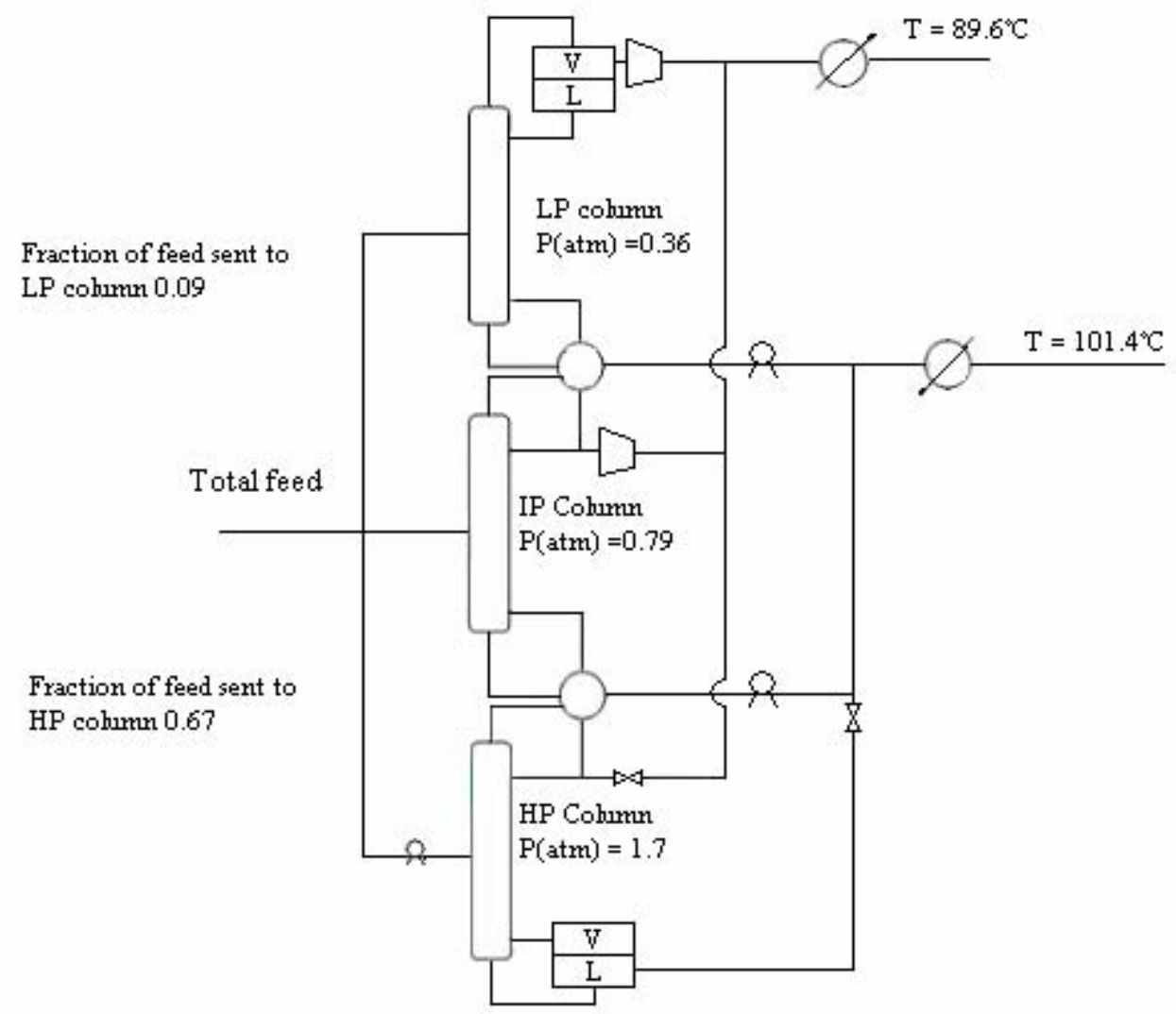

Fig. 17a Multieffect system for the beer column

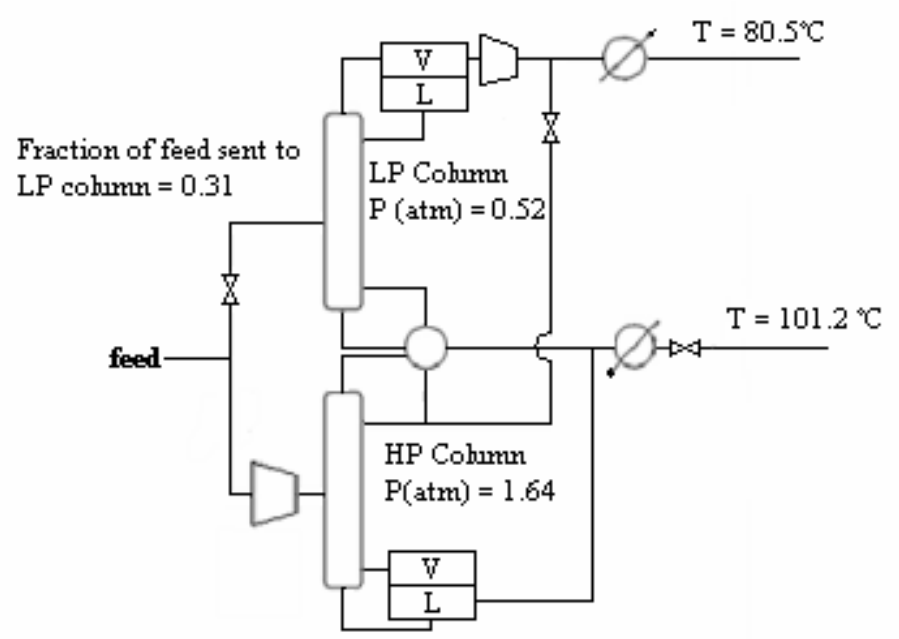

Fig. 17b Multieffect system for the rectification column 
The energy reduction in the system is shown in Fig. 18a and Fig. 18b with the help of T-Q diagrams (see Biegler et al., 1999) for the beer column and the rectification column.
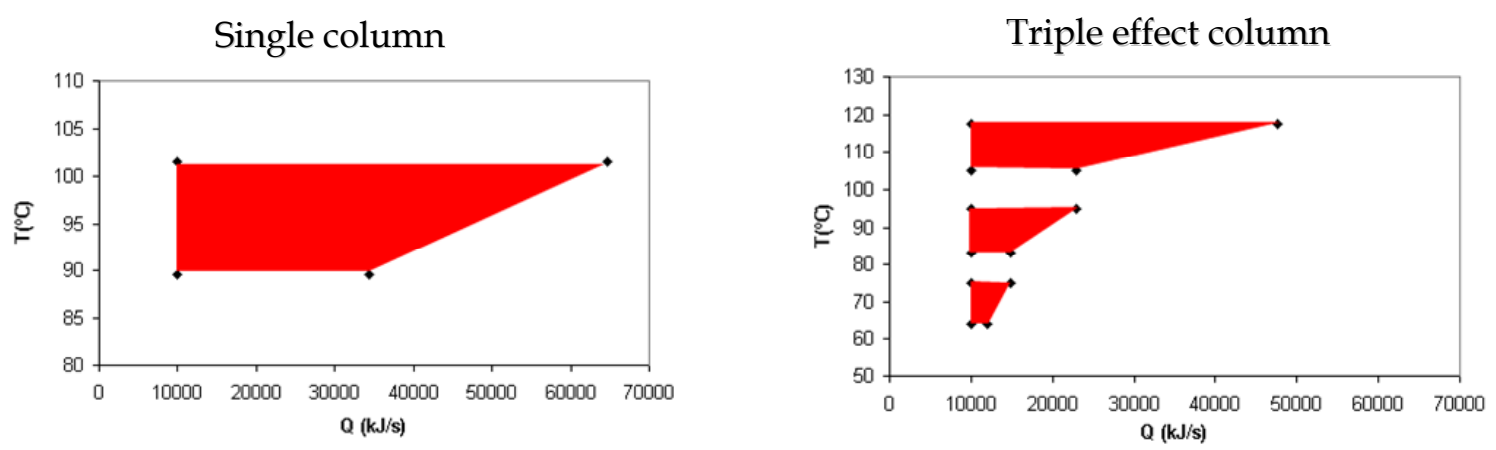

Fig. 18a T-Q diagrams for single column and multieffect beer column designs
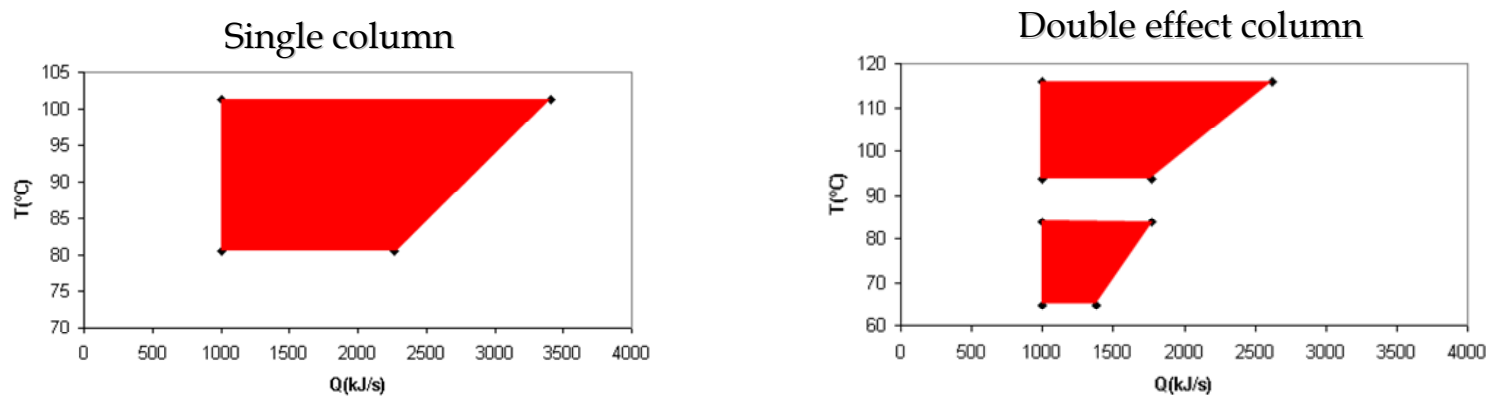

Fig. 18b T-Q diagrams for single column and multieffect rectification column designs

The overall T-Q curve on using multieffect columns shows the possibility of further heat integration in the plant and appears in Fig. 19. 


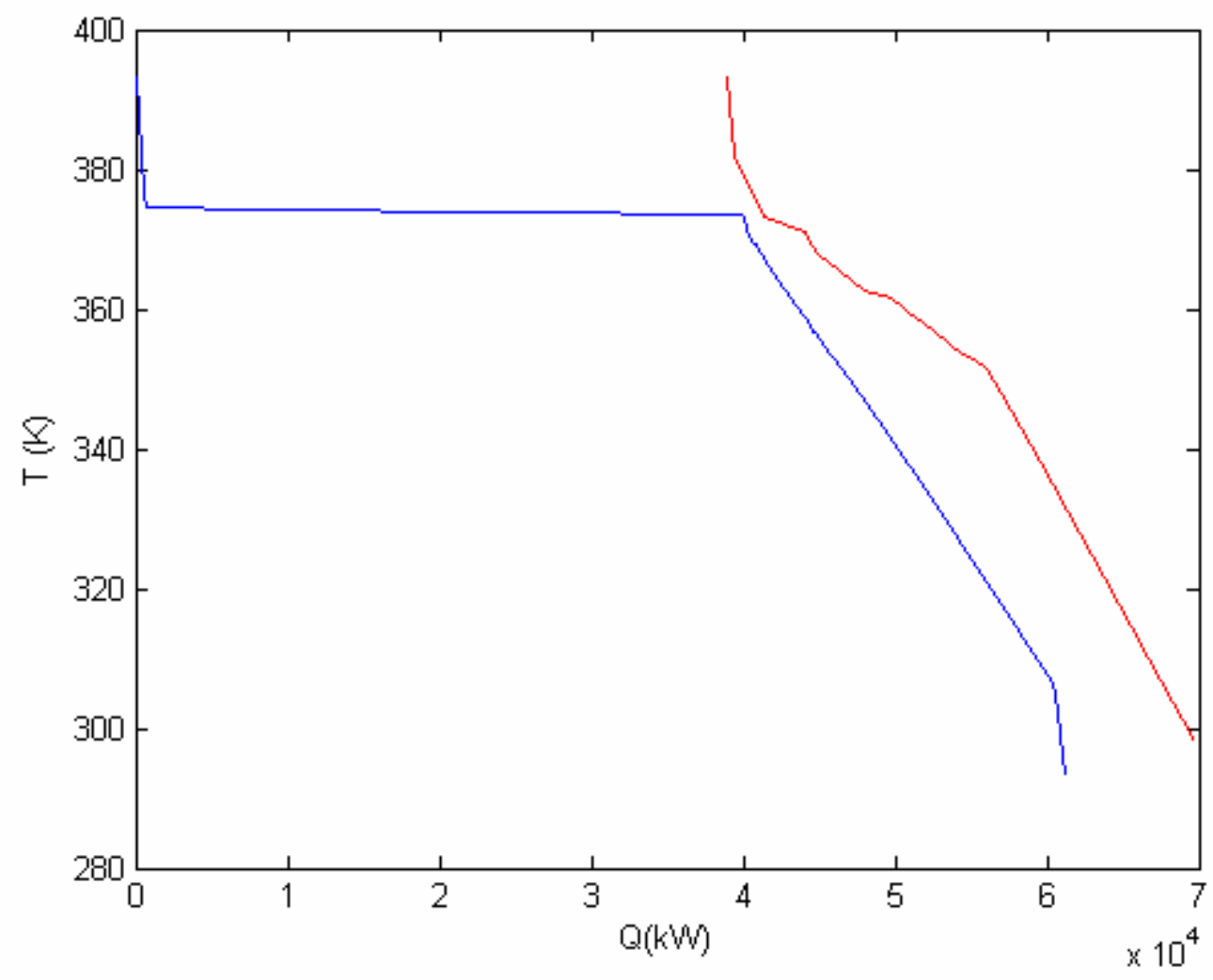

Fig. 19 T-Q curve after multieffect columns

On reducing the reflux ratios in the beer columns to 1.0 , and in the rectification column to 1.5 , and using the same combination of multieffect columns and heat integration in the plant, the calculated energy consumption reduces to $35,880 \mathrm{~kW}$ (equivalent to $17,276 \mathrm{BTU} / \mathrm{gal}$ ethanol produced), which corresponds to a production cost of $\$ 1.24 /$ gal ethanol produced. Comparing the energy values with the energy values reported in literature (Wang et al., 1999; Shapouri et al., 2002), we can see that this represents a considerable reduction in the energy consumed per gallon of ethanol produced. The detailed heat integration charts, multieffect column design computations and the cost analysis can be obtained from the authors.

\section{Conclusions}

In this work we have proposed a limited superstructure for designing optimal corn-based ethanol plants. A mathematical programming model consisting of mass and energy balances, thermodynamic equilibrium equations and design constraints was developed to represent the various operations in a bioethanol plant. The optimization of this model leads to a basic optimized design of such a plant. The results from this 
optimization were then used to incorporate structural enhancements in the distillation columns and heat integration inside the plant to reduce the overall steam consumption in the plant. We have applied the proposed model optimization and heat integration procedure to a case study of a dry-grind corn to fuel ethanol plant producing about $60 \mathrm{M}$ gal per year. As was shown by the results, significant reductions are possible in the energy input in the production of ethanol and in the manufacturing costs (from 79,003 $\mathrm{kW}$ to $35,880 \mathrm{~kW}$, and from $\$ 1.34 /$ gal to $\$ 1.24 / \mathrm{gal})$. Further improvements should be possible by pursuing a simultaneous optimization strategy, where the use of multieffect columns and heat integration is combined with the main model that is then optimized. Also, other alternatives such as the use of pervaporation to separate water and ethanol should be examined. Finally, more detailed simulation studies must be performed in order to validate the results presented in this paper. Despite some of the limitations, the results indicate that the dry-grind ethanol production process can be made more efficient, thereby making it more attractive as a sustainable alternative for liquid fuels.

\section{Acknowledgments}

The authors gratefully acknowledge financial support from the National Science Foundation under Grant CTS-0521769, the industrial members of the Center for Advanced Process Decision-making at Carnegie Mellon University, and from the Ministry of Education and Science of Spain.

Nomenclature

Indices

Ads $\quad$ corn grit bed adsorber

$B C \quad$ beer column

Col column

Cond condenser

d distillation column

Dry dryer

Fer fermentor

Flot flotation unit

Grind grinding unit 


$\begin{array}{ll}h & \text { selected components }\{\text { Ethanol, Water } \\ H X & \text { heat exchanger } \\ j & \text { component } \\ \text { Jet } & \text { jet cooker } \\ \text { Liq } & \text { liquefaction unit } \\ \text { MecP } & \text { mechanical press } \\ \text { Mix } & \text { mixer } \\ \text { MS } & \text { molecular Sieve } \\ p & \text { fermentation product } \\ \text { Premix } & \text { premixing tank } \\ \text { Rec } & \text { rectification column } \\ \text { Sac } & \text { saccharification unit } \\ \text { Snk } & \text { sink } \\ \text { Spl } & \text { splitter } \\ \text { Src } & \text { source } \\ \text { unit1, unit2 } & \text { process units in the system } \\ \text { wash } & \text { washing unit } \\ \text { WWT } & \text { wastewater treatment unit } \\ \text { Sets } & \\ \text { J } & \text { set of components } \\ P & \text { set of selected products from fermentation } \\ & \end{array}$

\section{Parameters}

$\begin{array}{ll}\text { ads_potential } & \text { mass } 1 \\ \text { ads_potential } & \\ A_{\text {ethanol }} & \text { mass of water adsorbed per unit mass of molecular sieve bed } \\ B_{\text {ethanol }} & \text { Antoine coefficient for ethanol } \\ C_{\text {ethanol }} & \text { Antoine coefficient for ethanol } \\ A_{\text {water }} & \text { Antoine coefficient for ethanol } \\ B_{\text {water }} & \text { Antoine coefficient for water } \\ C_{\text {water }} & \text { Antoine coefficient for water }\end{array}$




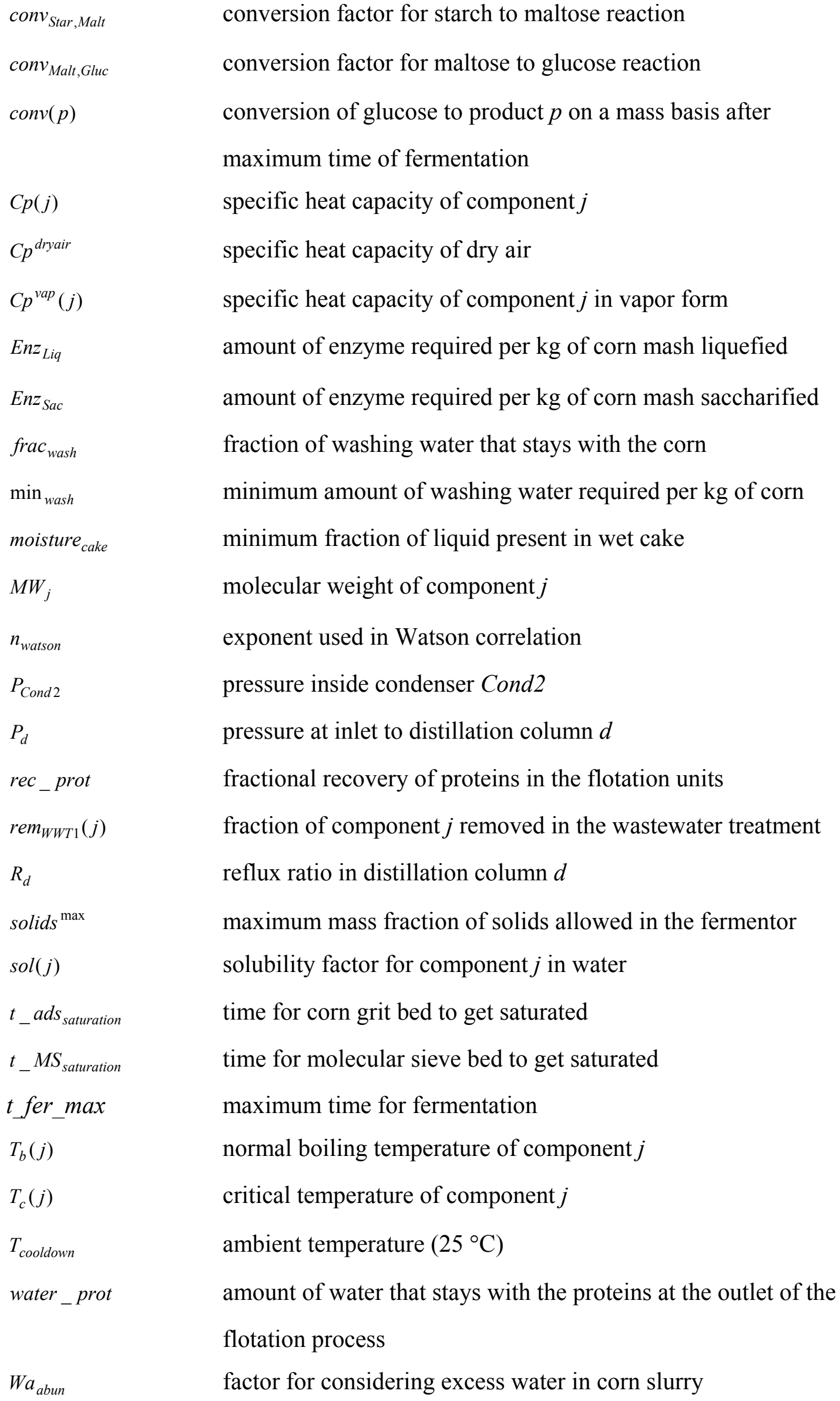




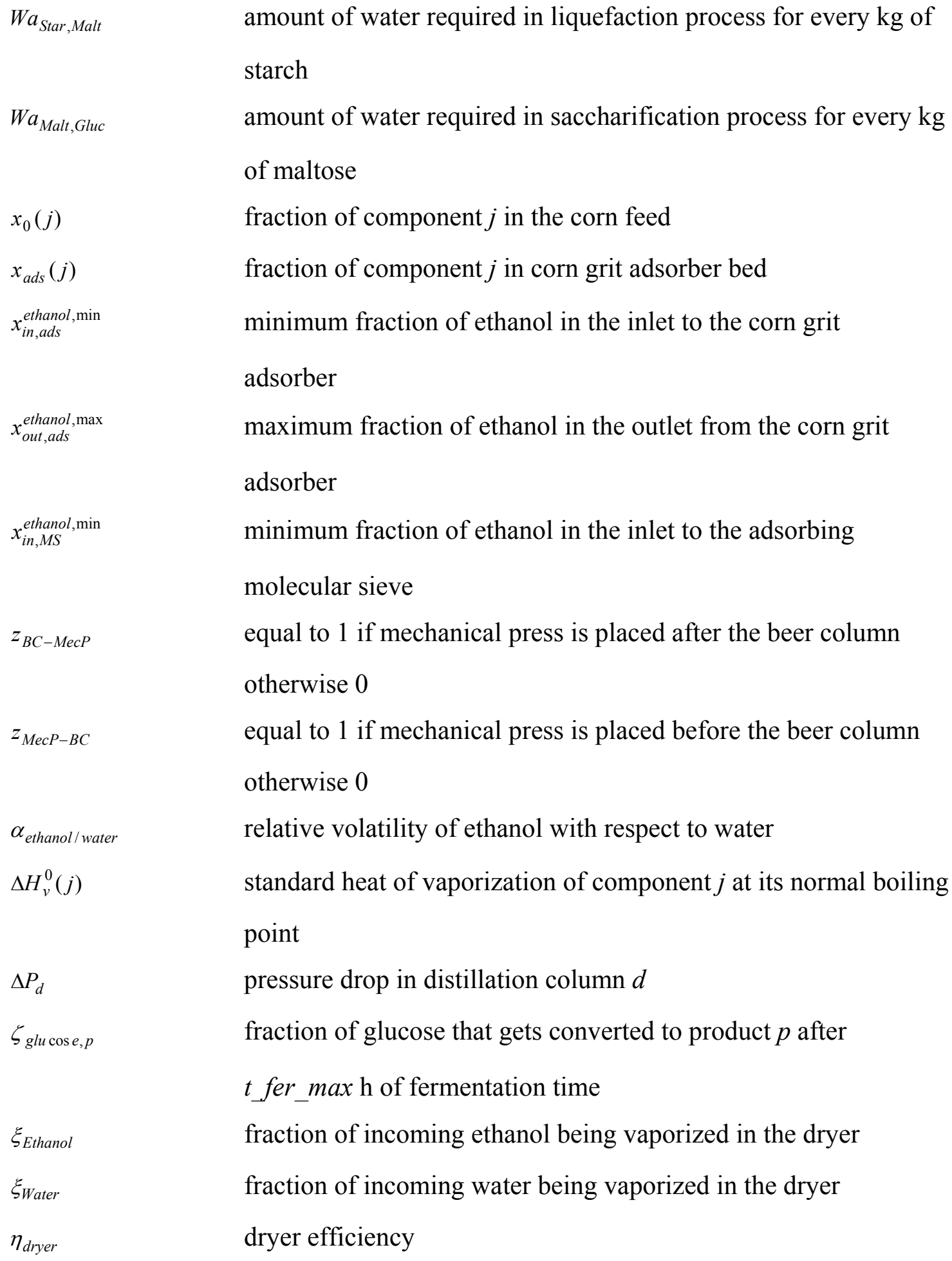




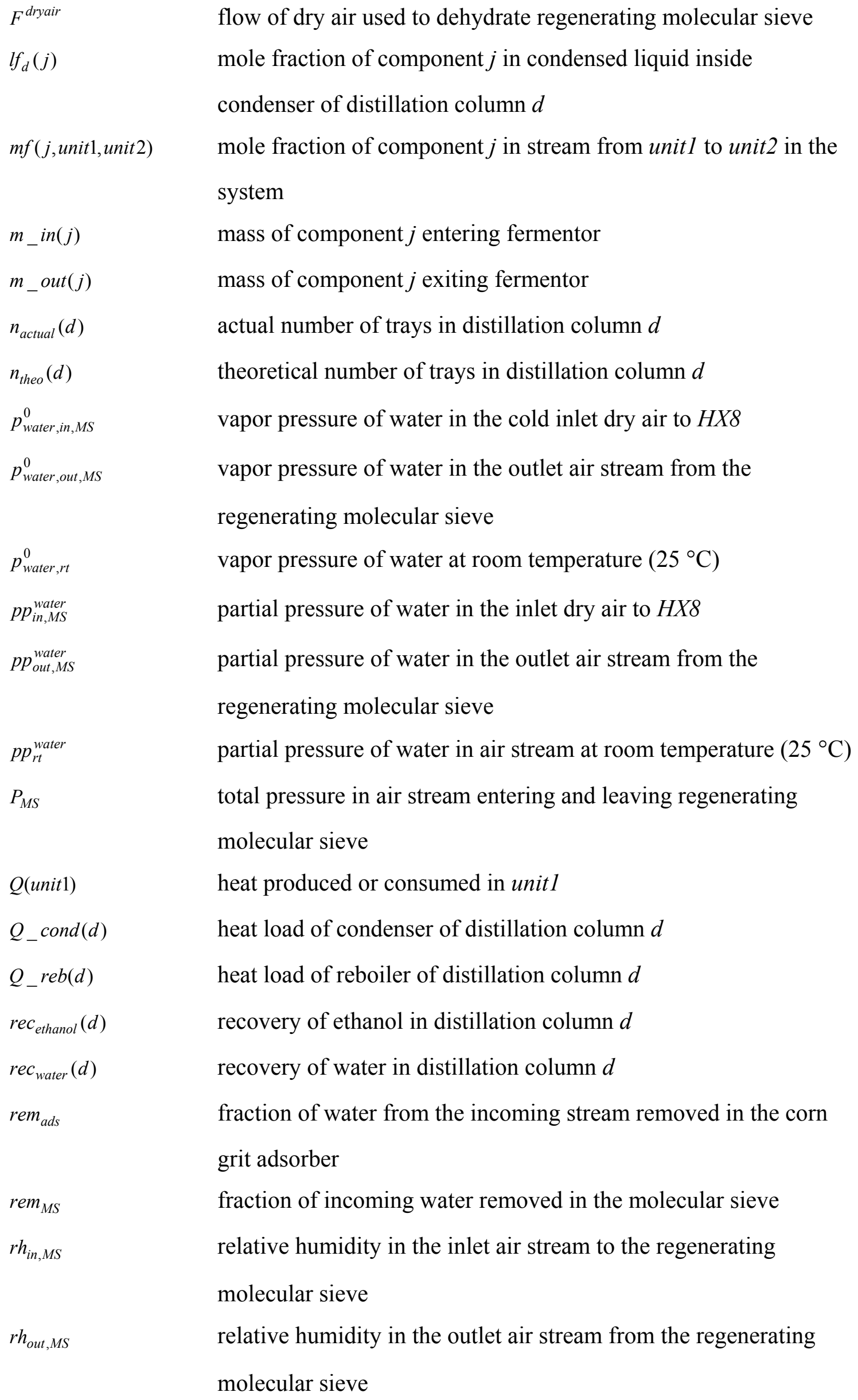




\begin{tabular}{|c|c|}
\hline$r h_{r t}$ & relative humidity in an air stream at room temperature $\left(25^{\circ} \mathrm{C}\right)$ \\
\hline$s h_{i n, M S}$ & $\begin{array}{l}\text { specific humidity in the inlet air stream to the regenerating } \\
\text { molecular sieve }\end{array}$ \\
\hline$s h_{\text {out }, M S}$ & $\begin{array}{l}\text { specific humidity in the outlet air stream from the regenerating } \\
\text { molecular sieve }\end{array}$ \\
\hline$s h_{r t}$ & specific humidity in an air stream at room temperature $\left(25^{\circ} \mathrm{C}\right)$ \\
\hline size $_{A d s 1}$ & mass of corn grit adsorption bed \\
\hline size $_{M S}$ & mass of molecular sieve bed \\
\hline split $_{M e c P 1}$ & fraction of water from the incoming stream that goes into the \\
\hline split $_{\text {MecP2 }}$ & $\begin{array}{l}\text { liquid stream outlet of mechanical press } M e c P 1 \\
\text { fraction of water from the incoming stream that goes into the } \\
\text { liquid stream outlet of mechanical press } M e c P 2\end{array}$ \\
\hline$t \_c y c$ & cycle time for fermentation \\
\hline t_fer & actual time of fermentation \\
\hline t_lag & lag phase time during fermentation \\
\hline$T($ unit 1, unit 2$)$ & temperature of stream between unit 1 and unit 2 in the system \\
\hline$x(j$, unit 1, unit 2$)$ & $\begin{array}{l}\text { mass fraction of component } j \text { in stream between unit } 1 \text { and unit } 2 \text { in } \\
\text { the system }\end{array}$ \\
\hline$x f_{d}(j)$ & $\begin{array}{l}\text { mass fraction of component } j \text { in condensed liquid inside } \\
\text { condenser of distillation column } d\end{array}$ \\
\hline
\end{tabular}

\section{References}

1. Alper, H.; Moxley, J.; Nevoigt, E.; Fink, G. R; Stephanopoulos, G.: "Engineering Yeast Transcription Machinery for Improved Ethanol Tolerance and Production”, Science, 314, 2006, 1565-1568.

2. Beery, K. E.; Ladisch, M. R.: “Adsorption of Water from Liquid-Phase Ethanol-Water Mixtures at Room Temperature using Starch-Based Adsorbents", Industrial and Engineering Chemistry Research, 40, 2001, 2112-2115.

3. Biegler, L.T.; Grossmann, I. E.; Westerberg, A. W.: "Systematic Methods of Chemical Process Design", Prentice Hall, New Jersey, 1999.

4. Dyck, K.; Ladisch, M. R.: "Dehydration of Ethanol: New Approach gives Positive Energy Balance", Science, 205, 1979, 898-900. 
5. Grossmann, I. E.; Caballero, J. A.; Yeomans, H.: "Mathematical Programming Approaches to the Synthesis of Chemical Process Systems", Korean Journal of Chemical Engineering, 16, 1999, 407-426.

6. IFQC (2004) Setting Quality Standard for Fuel Ethanol. International Fuel Quality Center. Hart Downstream Energy Services. DEH Ethanol Standard 18/2004 Report.

7. Ikegami, T.; Kitamoto, D.; Negishi, H.; Haraya, K.; Hiroyuki, M.; Nitanai, Y.; Koura, N.; Sano, T.; Yanagishita, H.: "Drastic Improvement of Bioethanol Recovery using a Pervaporation Separation Technique employing a Silicone rubber-coated Silicate Membrane”, Journal of Chemical Technology and Biotechnology, 78, 2003, 1006-1010.

8. Jacques, K.; Lyons, T. P.; Kelsall, D. R.: “The Alcohol Textbook", $3^{\text {rd }}$ ed., Nottingham University Press., United Kingdom, 1999.

9. Katzen, R.; Ackley, W. R.; Moon, G. D.; Messick, J. R.; Bruch, B. F.; Kavpisch, D. F.: “Low Energy Distillation Systems", $180^{\text {th }}$ National Meeting of the American Chemical Society, Las Vegas, NV, 1980.

10. Ladisch, M. R.; Voloch, M.; Hong, J.; Blenkowski, P.; Tsao, G. T.: “Cornmeal Adsorber for Dehydrating Ethanol Vapors", Industrial and Engineering Chemistry Process Design and Development, 23, 1984, 437-443.

11. Linhoff, B.; Townsend, D. W.; Boland, D.; Hewitt, G. F.; Thomas, B. E. A.; Guy, A. R.; Marsland, R. H.: “User Guide on Process Integration for the Efficient Use of Energy”, Institution of Chemical Engineers, Rugby, England, 1982.

12. Pimentel, D.: "Ethanol fuels: Energy Security, Economics, and the Environment", Journal of Agricultural and Environmental Ethics. Vol. 4, 1991, 1-13.

13. Reid, R. C.; Prausnitz, J. M.; Poling, B. E.: “The Properties of Gases and Liquids”, McGrawHill, New York, 1987.

14. Shapouri, H.; Duffield, J. A.; Graboski, M. S.: "Estimating the Net Energy Balance of Corn Ethanol”, Agricultural Economic Report No. 721. U.S. Department of Agriculture, Economic Research Service, Office of Energy, 1995.

15. Shapouri, H.; Duffield, J. A.; Wang, M.: "The Energy Balance of Corn Ethanol: An Update", Agricultural Economic Report No. 813. U.S. Department of Agriculture, Office of the Chief Economist, Office of Energy Policy and New Uses, 2002.

16. Singh, V.: "Past, Present and Future of Dry Grind Corn Process", 2006 Bioenergy Symposium, Purdue University, West Lafayette, IN, 2006.

17. Wang, M.; Saricks, C.; Santini, D.: "Effects of Fuel Ethanol Use on Fuel-Cycle Energy and Greenhouse Gas Emissions”, U.S. Department of Energy, Argonne National Laboratory, Center for Transportation Research, Argonne, IL, 1999.

18. Yee, T. F.; Grossmann, I. E.: "Simultaneous Optimization Models for Heat Integration - II, Heat Exchanger Network Synthesis”, Computers and Chemical Engineering, 14, 1990, 1165-1184. 


\section{Appendix A}

Table A1. Corn kernel composition on a wet basis

\begin{tabular}{|c|c|}
\hline $\begin{array}{c}\text { Component } \\
(j)\end{array}$ & $\begin{array}{c}\text { Mass fraction } \\
x_{0}(j)\end{array}$ \\
\hline Starch & 0.6185 \\
\hline Glucose & 0.0162 \\
\hline Protein & 0.076 \\
\hline Cellulose & 0.0274 \\
\hline Hemicellulose & 0.0638 \\
\hline Oil & 0.0354 \\
\hline Ash & 0.0127 \\
\hline Water & 0.15 \\
\hline
\end{tabular}


Table A2. Temperatures of various streams in network

\begin{tabular}{|c|c|}
\hline $\begin{array}{c}\text { Stream in } \\
\text { network } \\
\text { unit1,unit2) }\end{array}$ & $\begin{array}{c}\text { Temperature } \\
\text { T(unit1,unit2) } \\
\left({ }^{\circ} \mathrm{C}\right)\end{array}$ \\
\hline (Src1,Wash1) & 20 \\
\hline (Src2,Wash1) & 20 \\
\hline $\begin{array}{c}\text { (Wash1, } \\
\text { Grind1) }\end{array}$ & 20 \\
\hline (Grind1,Mix2) & 20 \\
\hline (Src3,Mix2) & 20 \\
\hline (HX1,Premix1) & 60 \\
\hline (Premix1,Jet1) & 60 \\
\hline (Jet1,Cook1) & 120 \\
\hline (Col1,Liq1) & 85 \\
\hline (Src5,Liq1) & 85 \\
\hline (Liq1,HX2) & 85 \\
\hline (HX2,Sac1) & 75 \\
\hline (Src6,Sac1) & 75 \\
\hline (Sac1,HX3) & 75 \\
\hline (Src7,Mix3) & 20 \\
\hline
\end{tabular}




\begin{tabular}{|c|c|}
\hline $\begin{array}{l}\text { (HX5_Snk5) } \\
\text { Stream in }\end{array}$ & Temperature \\
\hline network & $T($ unit 1, unit 2$)$ \\
\hline (unit 1 , unit 2 ) & $\left({ }^{\circ} \mathrm{C}\right)$ \\
\hline$(\mathrm{Mix} 3, \mathrm{Str} 1)$ & 32 \\
\hline (Str2,Spl1) & 32 \\
\hline (MecP1, Dry1) & 32 \\
\hline (MecP1,Flot1) & 32 \\
\hline (Flot1,HX4) & 32 \\
\hline (Flot1,Dry1) & 32 \\
\hline (Premix1,Jet1) & 60 \\
\hline (Dry1,HX10) & 100 \\
\hline (Dry1,Spl7) & 100 \\
\hline (HX10,Snk8) & 25 \\
\hline (HX11,WWT1) & 25 \\
\hline (HX12,MecP2) & 25 \\
\hline (MecP2, Dry1) & 25 \\
\hline (MecP2,Flot2) & 25 \\
\hline (Flot2,WWT1) & 25 \\
\hline (Flot2,Dry1) & 25 \\
\hline (Src8,HX8) & 20 \\
\hline (HX8,MS2) & 95 \\
\hline (MS2,HX9) & 95 \\
\hline (HX7,MS1) & 95 \\
\hline (MS1,MS2) & 95 \\
\hline$(\mathrm{MS} 1, \mathrm{Mix} 7)$ & 95 \\
\hline (Src9,HX6) & 20 \\
\hline (HX6,Ads1) & 91 \\
\hline (Ads1,Spl6) & 91 \\
\hline (Ads1,Spl5) & 91 \\
\hline (HX9,Snk4) & 25 \\
\hline
\end{tabular}

